\title{
As novas realidades do trabalho ${ }^{12}$
}

\author{
Huw Beynon ${ }^{3}$
}

Resumo: O escrito traz um panorama geral sobre as novas formas de trabalho, transformadas especialmente pela tecnologia, sobretudo pela produção de máquinas cada vez mais sofisticadas e pela extensão dos princípios que regem esta era ao escritório e a uma ampla gama de indústrias de serviços, aceleradas pelas TIC e pela revolução digital. Para isso, é desenhado um percurso no qual se parte dos estudos iniciais da sociologia do trabalho, passando pelo neofordismo e pós-fordismo, pelo trabalho estatal até os dias de hoje. Assim, discute-se sobre como tais tendências globais, se pensadas em escala mundial, serão o novo foco da sociologia do trabalho, visto que os gestores se esforçam para imaginar e criar um mundo no qual se diminuam ineficiências na produção, enfatizando as maneiras pelas quais as novas tecnologias facilitam as estratégias off-shoring a fim de manter as margens de lucro com base em trabalhos flexíveis de baixa qualificação.

Palavras-chave: Sociologia do trabalho; realidade do trabalho; transformações trabalhistas; revolução digital.

\section{The new realities of work}

1 Capítulo do livro: Beynon, H. (2015). 'Beyond Fordism', in Egdell S., Gottfried H. and Granter E., (Eds.), The Sage Handbook of the Sociology of Work and Employment, Sage, London, 306-328. Tradução de Breilla Zanon (bzaanon@gmail.com), com revisão técnica de Fernando Ramalho Martins.

2 Ao concluir este capítulo, sou muito grato à ajuda de meu amigo Theo Nichols e à correspondência que tive com Mark Vidal. Os comentários de Bob Carter e os de Steve Davies e Helen Sampson foram muito bem-vindos.

3 School of Social Sciences - Cardiff University - Cardiff - UK - beynonh@cardiff.ac.uk 
Abstract: This writing provides an overview of new ways of working, transformed especially by technology, especially the production of increasingly sophisticated machines and the extension of the principles governing the office age and a wide range of service industries, accelerated by ICT and the digital revolution. For this, it is designed a path that starts from the initial studies of the sociology of work, going through neofordismo and post-Fordism, by the state work until the present day. Thus, it is discussed how such global trends, if considered on a world scale, will be the new focus of labor sociology, as managers strive to imagine and create a world in which production inefficiencies are diminished, emphasizing the ways in which they work. which new technologies facilitate off-shoring strategies to maintain profit margins based on flexible low-skilled jobs.

Keywords: Sociology of work; reality of work; labor transformations; Digital revolution.

\section{A promessa}

A ideia de que os trabalhadores necessitam de mais controle sobre o trabalho, e de que os espaços de trabalho deveriam ser mais democráticos foi uma temática que se inseriu dentro dos movimentos trabalhistas nos Estados Unidos e na Europa durante o século XX (Coates; Topham, 1968). Nos anos de 1980, essas ideias tomaram um lugar central dentro da sociologia do trabalho. Embora partindo de uma perspectiva diferente, Piore e Sabel, em The Second Industrial Divide, apontaram para o desenvolvimento de crises no então estabelecido sistema de empregos e o potencial para mudanças positivas no mundo do trabalho possibilitadas pelas novas tecnologias. Com base nas experiências presentes na indústria de vestuário na Itália, eles anteciparam o renascimento de um novo sistema de produção artesanal - algo que eles chamaram de especialização flexível - que substituiria a linha de montagem e criaria empregos mais significativos.

Piore e Sabel associaram a crise social aos choques e pressões externas trazidas à tona pelas instabilidades do mercado global de mercadorias. Outros, teóricos da regulação, identificaram a crise como relacionada às contradições e pressões presentes dentro do sistema de produção classificado como Fordismo. Para esses autores, o ajuste entre capital e trabalho que ocorreu no pós-guerra, alcançado pelo estado de bem-estar social e as possibilidades produtivas da fabricação de linhas de montagem, atingiu seus limites na década de 1970. O que o pensamento desses teóricos da regulamentação compartilhava com Piore e Sabel, era a possibilidade de um novo tipo de formação capitalista emergindo 
das cinzas, com altas taxas de crescimento e processos de trabalho menos traumáticos, um arranjo que eles denominaram de "pós-fordismo"4.

Aqui então estaria a promessa: com a cooperação do trabalho, um novo tipo de ajuste poderia ser alcançado, que poderia não só estabilizar o emprego, mas produzir trabalhos criativos e satisfatórios. Essa foi uma promessa que não se cumpriu e a história sobre como esse futuro se perdeu é reveladora.

\section{Capitalismo em crise, transformações no trabalho e no emprego}

Nos anos de 1970, a Sociologia do Trabalho era dominada por debates em torno da tese desenvolvida por Braverman (1974), no sentido de que havia uma tendência embutida no próprio capitalismo de desqualificar a atividade laboral e promover a "degradação do trabalho". Essa tese foi baseada na análise da tentativa de Frederik Winslow Taylor em estabelecer os princípios de uma "gestão científica" que partia da observação e do cálculo das atividades dos trabalhadores nos Estados Unidos no final do século XIX. (F. W. Taylor, 1998). Esses princípios ficaram conhecidos como "taylorismo" e foram desenvolvidos duas décadas mais tarde por Henry Ford em sua fábrica de automóveis em Dearborn, onde veículos eram produzidos por meio da operação de uma linha de montagem em movimento. Esse sistema foi facilitado pela produção de peças padronizadas, e uma corporação verticalmente integrada. Tal sistema ficou reconhecido como Fordismo e foi descrito por Doray da seguinte forma:

A fábrica foi desenvolvida para produzir um objeto padronizado... com uma maquinaria padronizada e métodos padronizados. Era uma estrutura coerente que poderia ser reproduzida e sob a qual o trabalho humano era padronizado e considerado uma extensão do sistema de máquinas. (Doray, 1988: 70)

Naquele tempo esse sistema foi visto como revolucionário e a epítome do modernismo, admirado por Lenin e pelo comunista italiano Gramsci (1971), que viam no sistema, com sua construção eficiente em torno de uma maquinaria elaborada, os ingredientes de um novo e moderno ser humano. Em meio a tudo isso, as características potencialmente opressoras do Fordismo eram esquecidas. Contudo, assim que o Fordismo se tornou um "ideal regulatório da gestão Ocidental", a atenção se voltou para a forma pela qual "as hierarquias da gestão sistematicamente despiram o trabalhador de sua autonomia e conhecimento por meio de uma divisão do trabalho altamente integrada" (McKinlay; Starkey, 1994: 190). O seu sucesso como sistema de produção eficiente, capaz de

4 Essa formulação e seu fundamento histórico foram fortemente contestados. Ver Brenner; Glick (1991), Clarke (1992); Sayer; Walker (1992). 
aumentar as taxas de produtividade e os lucros foram questionados. Sendo assim, o período pós-guerra (para Brenner (2006), o "grande boom”, para Marglin e Shor (1992), a "era de ouro do capitalismo") foi identificado pelos escritores regulacionistas como o ponto mais alto do "Fordismo", um termo que para eles conectava a macroeconomia e os fatores institucionais ao sistema de trabalho e a organização da vida dentro dos ambientes de trabalho (Lipietz, 1987). Foi o colapso desses arranjos mais amplos associados a um "compromisso de classe" entre capital e trabalho, junto com a ascensão da nova tecnologia da informação, que levou à mudança de ênfase dentro do estudo sociológico sobre o trabalho; afastando-se da "desqualificação" e se aproximando de uma ideia mais otimista a respeito do "pós-fordismo" e da "especialização flexível".

O Fordismo era mais claramente identificado com a montagem de carros e qualquer debate sobre a transformação do trabalho precisa começar por aí, e pela Ford Motor Company. No período pós-guerra, a Ford expandiu suas atividades além mar e consolidou sua presença no Ocidente atlântico por meio da Ford europeia. Ao fazer isso, fortaleceu seu poderoso sistema de engenharia de produção e marketing, aliado com uma aproximação vigorosa e direta às relações de trabalho. Esse "Fordismo" permaneceu ascendente e inalterado até o fim dos anos de 1970 quando, nos Estados Unidos e na Europa, a Ford e outras companhias automobilísticas passaram a sofrer pressão dentro de suas próprias fábricas e também de forças externas, mercadológicas, a partir da importação de carros produzidos no Japão. Esses elementos trouxeram os ingredientes de uma crise econômica, com excesso de capacidade nos dois maiores mercados e um evidente estreitamento dos lucros (Glyn e Sutcliffe, 1972)5. Dentro das fábricas, $o$ aumento ano-a-ano da produtividade associado às décadas de crescimento começou a se estabilizar, e as companhias entraram em conflitos trabalhistas à medida em que os trabalhadores reagiam contra as pressões do trabalho e a falta de autonomia. Greves, absenteísmo e outras formas de não-cooperação se tornaram endêmicas. Algumas dessas pressões foram capturadas por relatos de fábricas mundo a fora: nos Estados Unidos (Hamper, 1986; Pfeffer, 1979), no Reino Unido (Beynon, 1973), Itália (Bastrani, 2016, primeiramente publicado em 1971; Partridge, 1986), Alemanha (Wallraff, 1977) e França (Linhart, 1981). Esses problemas de gestão encorajaram discussões sobre a reforma da linha de montagem, e isso foi particularmente evidenciado na Suécia (Palm, 1977) onde

5 Mais recentemente, Michael Roberts documentou essa tendência na taxa de lucro, desenvolvendo a estrutura delineada por Marx em: Disponível em: <https://thenextrecession.wordpress.com/2013/12/16/us-rate-of-profit-up-slightly-in-2012-flat-in-2013-down-in-2014/>. Acesso em: 11 set. 2019. Disponível em: $<$ thenextrecession.wordpress.com/so11/11/20>. Acesso em: 
a rotação de cargos foi introduzida como forma de lidar com a monotonia do trabalho e também como forma de democratizar o ambiente laboral. Foi na França que a resposta foi mais complexa e onde um dos fundadores da Escola da Regulamentação, Lipietz, escreveu de uma forma mais revolucionária. Para ele, a crise no ambiente de trabalho era parte de uma crise generaliza que prefigurava o colapso de um consenso estabelecido sob o qual o progresso técnico e social estaria ligado e baseado em um "empobrecimento do trabalho", e onde o estado burocrático dominado pelos tecnocratas "havia imposto sua concepção de bom e belo" sobre as pessoas (Lipietz, 1992: 343).

\section{Produção enxuta, neofordismo e pós-fordismo}

Essa sensação de crise na indústria automobilística aumentou devido ao crescente número de carros japoneses importados vendidos mais do que os produzidos pelos mercados do Reino Unido e dos EUA. Logo, essas importações foram substituídas pela concorrência direta das filiais japonesas (chamadas de "transplantes" nos EUA). Em resposta, a Ford introduziu um novo programa de produção chamado "AJ" visando mudar as relações de trabalho com a adoção de um estilo de gestão mais participativo combinado com a persistente ameaça de fechamento das fábricas e (sob o projeto Erika) com a crescente automação (Starkey e McKinlay, 1994). Isso foi traduzido nas suas fábricas do Reino Unido sob slogans de parede que informavam números da produção de diferentes fábricas da Ford visando incentivar a conclusão rápida e eficiente de todos os carros, com um aviso adicional: "se vê uma lacuna - há um Japonês" (Beynon, 1985). Esta estratégia de "japonização" espalhou-se pelas grandes montadoras (Elger; Smith, 1994) e ficou conhecida como "produção enxuta" (Womak et al., 1990). Foi isso que, na visão de Vidal, tornou-se o "processo de trabalho manufatureiro pós-fordista por excelência” (Vidal, 2012).

A produção enxuta foi um avanço do sistema desenvolvido pela Toyota e baseado nas observações da empresa sobre o sistema Ford nos EUA na década de 1950. De maneira famosa, envolve o sistema de luzes Andon - verde, âmbar e vermelho - sinalizando o estado de produção através das seções. Esse sistema foi construído em torno de três elementos separados que foram codificados e copiados: uma ênfase na melhoria contínua (kaizen), apoiada por um estilo mais participativo de gestão e, mais notavelmente, um sistema just-in-time de produção de controle de estoque como parte de um programa de redução de desperdício.

6 Nota: Abreviação para After Japan (depois do Japão).

7 No original: "see a gap - there's a Jap" 
A implementação desses processos enxutos em toda a manufatura foi desenvolvida por meio do Total Quality Management (TQM) - Gestão da Qualidade Total, e envolveu uma revolução na organização dos ambientes de trabalho, especialmente ao enfatizar o trabalho em equipe e os líderes de equipe em vez de supervisores. Se inicialmente reagiu-se positivamente às mudanças (Florida e Kenny, 1991), relatórios de pesquisa mais detalhados, baseados na experiência de pessoas que trabalhavam sob o novo sistema, mostravam-se mais desanimadores. Nos EUA, Laurie Graham (1994a e b) forneceu uma "visão da linha de montagem" que enfatizava as maneiras pelas quais o "trabalho em equipe" produzia intensos e diferentes tipos de estresse, de modo a associar a produção enxuta ao "gerenciamento por estresse" (Barker, 1993; Parker e Slaughter, 1988). No Reino Unido, Wood (1987) passou um turno nas linhas de montagem da Nissan em Sunderland e descobriu que ele tinha "pouca ideia de quão duro era o trabalho, ou que, aos 36 anos, era realmente velho demais para isso". Delbridge (1997) teve uma experiência semelhante, se bem que mais longa, como estudante de doutorado e descreveu o trabalho como mais difícil e mais destrutivo para a alma do que ele previra. Outros estudos vieram apoiar uma visão da produção enxuta como envolvendo mudanças, mas não satisfazendo nenhuma das esperanças de maior autonomia de trabalho e satisfação no trabalho (Lewchuk; Robertson, 1997; Milkman, 1997). Em um estudo de acompanhamento da fábrica da Ford em Broadmeadows, na Austrália, Constance Lever-Tracy (1990) concluiu que a produção enxuta e seu estilo de gestão participativo não "envolviam nenhuma mudança fundamental na natureza básica do fordismo, ou constituíam qualquer passo importante no caminho para a democracia no trabalho". Conti e Warner (1993) chegaram a uma conclusão semelhante, vendo o "trabalho em equipe" como algo envolvendo algumas pessoas que se juntavam no começo de um turno que era então dominado pelas mesmas tarefas árduas e repetitivas.

No entanto, demandas por mudanças e melhorias continuaram. No Canadá, uma aliança comercial entre a General Motors e a Suzuki pretendia desenvolver um processo de trabalho que "traria poucos ou nenhum traço do fordismo". Um estudo longitudinal do projeto (Rienhart et al., 1997) concluiu que, apesar da grande esperança, a visão geral dos trabalhadores era de "apenas uma outra fábrica de automóveis". Naquele mesmo ano, uma pesquisa com trabalhadores da indústria automobilística conduzida pela McMaster University e pelo sindicato canadense de trabalhadores automotivos constatou, entre outras coisas, que mais da metade dos funcionários ( $80 \%$ da GM) sentiam que precisavam trabalhar o mais rápido possível por pelo menos $50 \%$ do tempo para evitar ficar 
para trás. Na mesma pesquisa, apenas 13\% dos trabalhadores da GM e $26 \%$ e $32 \%$ da Chrysler e da Ford (respectivamente) sentiram que poderiam trabalhar nesse mesmo ritmo até os 60 anos (Lewchuk et al., 2001). Uma pesquisa posterior sobre trabalhadores da indústria automobilística no Reino Unido concluiu que o novo sistema era caracterizado por uma "pressão constante para reduzir os custos" (Stewart et al., 2009). Na visão desses autores, a ênfase nos custos era tão forte que anulou os elementos participativos e, "em vez de estabelecer um novo regime de democracia industrial em um setor manufatureiro próspero, a produção enxuta exige subordinação do trabalho" (p. X). Na visão deles, o Fordismo clássico estava sendo substituído por um fordismo sem sindicatos ou provocações por parte dos subordinados, ecoando um relato da fábrica da Ford de Liverpool, realizado vinte anos antes (Beynon, 1985).

Esses e outros estudos desafiaram as vozes utópicas associadas à promessa de regimes de trabalho menos severos e pós-fordistas. Mas eles também confirmaram que mudanças estavam ocorrendo na organização e na experiência de trabalho na Europa e nos EUA, associadas à influência dos métodos de produção japoneses. A modificação e o ajuste nos sistemas de produção, juntamente com a experimentação em novos locais, tornaram-se familiares para a maior parte da indústria manufatureira. Embora isso tenha produzido uma variedade de combinações de formas, foram poucos os exemplos de melhorias significativas nos níveis de autonomia dos trabalhadores. Essa conclusão foi confirmada por um estudo na Bélgica que documentou essas mudanças em quatro setores, mas concluiu que as descobertas sugeriam um conceito de "neo" em lugar de "pós" taylorismo ou fordismo (Huys et al., 1999).

Vidal está de acordo, mas ainda acha útil usar a noção de "pós", que, despido de todos os seus elementos utópicos, é simplesmente indicativa de uma nova e diferente forma de extração de excedente com uma série de elementos que estão intimamente associados à mudança para o neoliberalismo. Neste, a subcontratação é talvez o desenvolvimento mais significativo, juntamente com as mudanças relacionadas que ocorreram no contrato de trabalho. Aqui se vê o surgimento de trabalhadores terceirizados temporários e de empregados temporários.

Uma característica central do fordismo era a integração vertical da corporação e, com ela, a incorporação da força de trabalho corporativa em acordos de negociação coletiva. Dentro de uma fábrica de automóveis havia uma gama de trabalhos não diretamente associados à produção - a limpeza da fábrica seria um exemplo. Sob o clássico regime fordista esses empregos seriam incluídos na negociação coletiva, eles também estariam abertos a empregados da linha 
de produção seniores que passaram a achar fisicamente difícil a intensidade da linha de produção. Sob a produção enxuta, muitos desses empregos foram desmembrados e terceirizados para empresas especializadas, com impacto direto nos salários (Bernhardt et al., 2001; Vidal, 2013b), ao mesmo tempo em que as montadoras, enfatizando sua necessidade de se concentrar em "capacidades essenciais", exerceriam pressão sobre a cadeia de fornecimento no que diz respeito às operações de seus fornecedores. É aqui que há a ruptura mais clara com 0 fordismo, e que deixa o trabalho empobrecido.

Essa visão distópica é compartilhada por Vidal, que, por meio de uma linha diferente de argumentos, vê esse novo modo de acumulação como profundamente "disfuncional" e qualquer coisa menos transicional (Vidal, 2013a). É "o novo normal". Aqui, a capacidade das montadoras automotivas de "externar" seus custos de mão-de-obra para outras empresas especializadas, forçadas a concorrer pelo subcontrato, tornou-se uma característica geral do novo sistema de emprego, distribuído entre a industrialização e os serviços das indústrias emergentes ${ }^{8}$. As consequências desses desenvolvimentos foram significativas. A terceirização tem sido a principal causa da crescente disparidade de renda de norte a sul do Reino Unido e dos EUA. A redução de salários e condições nas empresas terceirizadas também tem sido um fator importante na sustentação da reprodução de empregos de baixa remuneração e baixa autonomia nessas duas economias (Bernhardt et al., 2001; Goos e Manning, 2007; Vidal, 2013b).

\section{Novas regras do varejo}

Na primeira década do século XXI, mais de $80 \%$ dos empregos no Reino Unido e nos EUA envolviam a prestação de serviços, seja diretamente ao consumidor (como em um restaurante) ou a outra empresa (como os limpadores terceirizados em uma fábrica de automóveis). A maioria desses trabalhadores eram mulheres, especialmente aquelas nos "trabalhos de serviço de rotina" eloquentemente descritos por Reich (1991)9. Apesar de muitas mulheres terem trabalhado na manufatura durante o período de alto fordismo, elas eram minoria e a maioria das principais indústrias era dominada por homens. Aqui talvez

8 Um estudo sobre a terceirização de serviços do setor de refeições, TI, gerenciamento de instalações, serviços de emprego, suporte de escritório, consultoria técnica e outros serviços estimou que em 2010 eles empregavam 3,3 milhões de pessoas, representando 12,25\% de todos os funcionários no Reino Unido (Oxford Economics, 2012).

9 Dada essa mudança, é surpreendente que grande parte da discussão sobre o fordismo e o pós-fordismo tenha se preocupado apenas com a manufatura e com setores em que a força de trabalho é predominantemente masculina (Herouvim, 1989: 589). 
seja a ilustração mais dramática do modo como a organização do trabalho e do emprego mudou. Nas décadas de 1950 e de 1960, os maiores empregadores eram corporações privadas ou públicas que operavam na indústria e na manufatura pesadas. Não é assim hoje, quando os dois maiores empregadores privados do mundo são o Walmart (2,1 milhões de funcionários em todo o mundo) e as franquias de fast food do McDonald's (1,9 milhão). Tão significativos foram esses desenvolvimentos, que sociólogos enxergaram como sendo emblemáticos de um novo sistema - Waltonism em Vidal (2012) e McDonaldização em Ritzer (1993). Ritzer, de fato, viu o desenvolvimento da indústria de fast food com hambúrgueres sendo "montados e, às vezes, cozinhados em uma linha de montagem" (193: 484) como um "desenvolvimento verdadeiramente revolucionário". A revolução, no entanto, não se encaixa na promessa e nas primeiras visões utópicas do pós-fordismo. Ao contrário, ela relaciona-se à extensão do processo de trabalho fordista, com a ajuda de princípios enxutos, no campo de restaurantes e refeições. Aqui, no entanto, e diferentemente da manufatura, os empregos (embora igualmente repetitivos e com baixa qualificação e pouca discrição) são de baixa remuneração, e muitas vezes em período parcial e sem sindicalização.

Vidal seleciona um padrão similar e mais amplo de mudança relacionados aos supermercados e ao varejo de maneira mais geral. No Walmart (que domina o varejo nos EUA e tem uma forte presença no Reino Unido, sendo proprietário da Asda), ele vê o desenvolvimento mais radical do novo modelo de subcontratação com os grandes varejistas exercendo seu poder econômico sobre seus inúmeros fornecedores, reduzindo as médias salariais e aumentando o rigor sobre o controle do trabalho (Vidal, 2012) ${ }^{10}$. Aqui, nós temos um círculo, de natureza menos virtuosa, com um setor de varejo enxuto fornecendo alimentos baratos, refeições prontas e bens para famílias com pouco tempo, cujos salários reais estavam sendo arrochados (Lichtenstein, 2006; Parker, 2013).

Com uma alta proporção de seus custos atrelados ao trabalho, o "supermercado" revolucionou o comércio de alimentos. Deslocado para locais de baixo custo, longe dos centros das cidades, o novo shopping self-service surgiu como uma forma de reduzir os custos de mão de obra e racionalizar o relacionamento com o cliente. $\mathrm{O}$ vendedor se tornou o operador que apenas confere e a "desqualificação da força de trabalho facilitou, acentuou e reforçou outro

10 Essa identificação do varejo com o lado mais sombrio do mundo além-fordismo é irônica, dada a saliência do setor dentro de visões utópicas anteriores, nas quais a Benetton foi a figura central. Como disse Robin Murray: “a base para o novo sistema não estava na fabricação, mas no varejo ... a revolução do varejo reflete novos princípios de produtividade, um novo pluralismo de produção e uma nova importância da inovação. Como tal, marca a mudança para a era pós-fordista” (Murray, 1988: 11). 
desenvolvimento importante - o crescimento do trabalho feminino em tempo parcial" (Du Gay, 1993: 572). Aqui o Waltonism reproduziu o outro elemento-chave do mundo pós ou neo-fordista, com a hierarquia estendida da corporação fordista sendo substituída por uma estrutura achatada onde a maioria se localiza na base sem escada para levá-los para cima (Grimshaw et al., 2002). Aqui muitos trabalham como empilhadores de prateleiras, e Barbara Ehrenreich compartilhou sua experiência quando ela conseguiu um emprego na loja Walmart em Minneapolis (Ehrenreich, 2001). Lá, ela foi surpreendida com uma prática administrativa que seria muito familiar ao próprio Henry Ford. Ford, assim como Taylor, achou o "desperdício" intolerável e a perda de tempo, imperdoável. Em sua opinião, era de responsabilidade da gerência garantir que o trabalhador tivesse "todos os segundos necessários, mas nenhum segundo desnecessário". Os trabalhadores eram pagos para trabalhar, não para falar ou para sorrir (Beynon, 1973). Assim era também no Walmart, onde a gerência e seus "espiões" patrulhavam a loja, procurando trabalhadores que estivessem falando de algo que não fosse trabalho. Novos recrutas são alertados sobre o "roubo de tempo", definido como "fazer qualquer outra coisa além de trabalhar no tempo da empresa: qualquer coisa mesmo" (Ehrenreich, 2001: 146).

As compras são coordenadas eletronicamente no supermercado self-service. O leitor de código de barras posicionado na área de check-out oferece um nexo permanente com a central de pedidos por meio de um sistema conhecido como EPOS (Electronic Point of Sale). O trabalhador desliza o produto sobre o leitor, que elabora a fatura do cliente e permite que a alta administração analise detalhadamente os números das vendas (ver Harvey et al., 2002). Dessa forma, técnicas de produção enxuta foram aplicadas aqui e em várias indústrias de serviços. Na Tesco, por exemplo, a área gerencial estrutura-se em um desenho circular, onde cada área operacional da loja é avaliada diariamente com símbolos de cor vermelha, âmbar ou verde - como no sistema de luzes Andon (Beynon et al., 2001).

As entregas para as lojas são organizadas por meio de uma série de centros de distribuição regionais (RDCs) que racionalizam e mecanizam o complexo processo logístico associado à proteção e distribuição de uma ampla variedade de produtos. Alguns desses RDCs são de propriedade da própria cadeia de supermercados, sendo principalmente terceirizados para grandes empresas de logística independentes, como Exel e Wincanton. Um RDC de tamanho médio irá lidar com entre 500.000 e 1 milhão de caixas de produto por semana, com algo entre 1.000 e 2.000 caminhões sendo carregados e retirados a cada dia. Esse carregamento é realizado por trabalhadores ("catadores") que viajam pelo 
armazém em empilhadeiras, localizando e escolhendo as caixas necessárias; tudo conforme as exigências do relógio. Como um gerente explicou:

As coordenadas de cada ponto de carregamento são medidas. Então, [o escâner] sabe o quanto você se deslocou em cada tarefa. Um catador irá junto e coletará um conjunto de etiquetas em um palete, e ele saberá que tem onze minutos e meio para fazer aquele produto, fazer aquele palete. (Harvey et al., 2002: 222)

A revolução no varejo descrita aqui foi levada um passo adiante com a aplicação dos princípios enxutos e da digitalização no mercado de encomendas pelos correios (antes convencional). Aqui, a Amazon tem sido o principal impulsionador, com seus armazéns semelhantes a hangares de aeronaves, agora superando muitos RDCs. Carol Cadwalladr (2013) esteve em um deles, em South Wales, como funcionária de uma agência, e ouviu esse local sendo descrito como um "centro de realização", dentro do qual ela era uma "associada". Ela explica que em seu segundo dia "o gerente nos contou que só nós havíamos apanhado 155.000 itens nas últimas 24 horas. Amanhã... esse número ficará mais próximo de 450.00o". Para isso, ele acrescenta "não selecionamos e embalamos ... selecionamos e embalamos os itens certos e os enviamos para os clientes certos". Na semana seguinte, eles aprenderam que as horas seriam mais longas, com horas extras obrigatórias a cada dia, além de um turno adicional.

A Amazon se descreve como "a empresa mais centrada no cliente da face da Terra". Seus trabalhadores, em contraste, parecem ser menos prioritários. Durante um turno, os catadores caminham 15 milhas ${ }^{11}$, muitas vezes iniciando suas pausas para refeição a cinco minutos da cantina e do banheiro, sempre "coletando" - minuto a minuto. A falta de remorso envolvida nesses relatos é uma reminiscência da linha de montagem que nunca para. Aqui, a linha é substituída pelos escâneres que os catadores transportam, que permitem que sua atividade seja rastreada e que a empresa produza "relatórios de inatividade" (Scholz, 2015). Aqui também as pessoas aprendem maneiras de sobreviver. Como um trabalhador de armazém em Jefferson Indiana explica:

para permitir tempos de intervalo mais longos e impedir que eles tomem o tempo do almoço, [catadores] pegam o último item que pretendem digitalizar, cerca de três minutos antes do início do intervalo, aproximam-se o máximo possível da frente do piso em que estão trabalhando, então digitalizam

11 O que equivale a cerca de 24 quilômetros. 
exatamente um minuto antes de começar a pausa. Isso dá um pouco mais de tempo para guardar o carrinho e descer até a área de descanso, sem que a gerência os rastreie e indague por que pararam de coletar três minutos antes do intervalo. (Nolan, 2014a)

Comentários como esses são profundamente familiares aos primeiros tempos das fábricas, assim como as experiências dos gerentes de linha de frente responsáveis pelo funcionamento eficiente do sistema. Tendo saído da Amazon, um deles explica como:

eu deveria trabalhar como gerente de contas, mas acabei com um trabalho completamente diferente na equipe de qualidade (a Amazon é tão vasta em gerenciamento enxuto e eu trabalhei como especialista em Kaizen). ... Mudanças repentinas das funções de trabalho são muito comuns na Amazon. Eu trabalhei para um gerente que dormia em seu carro aos domingos para que ele pudesse estar bem cedo no escritório para a revisão semanal da empresa com a alta gerência. (Nolan, 2014c)

Outro gerente, que trabalhou no escritório de Seattle, chamou a atenção para uma prática de $\mathrm{RH}$ estabelecida pela empresa onde

Você literalmente é re-entrevistado para o seu cargo, constantemente, enquanto o ocupa. Isso ocorre pelo menos a cada três meses. E você continua recebendo lembretes de que as pessoas de fora cobiçam o seu trabalho! Trata-se de um ambiente de trabalho muito estressante. (Nolan, 2014b)

O escritório de Seattle apareceu na investigação do New York Times, que teve como foco o fato de que a empresa estava "realizando um experimento pouco conhecido sobre até onde poderia pressionar os trabalhadores de colarinho branco" (Kantor e Steitfeld, 2015). Em seus cuidadosos apontamentos sobre as operações da Amazon na UE e nos EUA, Simon Head concluiu que estas se caracterizavam por uma "mistura venenosa de taylorismo e stakhanovismo", entremeada com a TI do século XXI e com uma cultura difundida de mesquinhez e desconfiança” (2014: 42).

Apesar desses excessos, a Amazon é vista como um negócio extremamente bem-sucedido e, como aponta Head, seu fundador, Jeff Bezos, ficou em segundo lugar no ranking mundial dos diretores executivos mais admirados, realizado

12 Esta é outra referência à União Soviética dos anos entre guerras, quando trabalhadores altamente produtivos (como Stakanov) foram identificados como heróis nacionais. 
pela Harvard Business Review em 2012 e a própria empresa ficou em terceiro lugar na lista mundial da CNN (Head, 2014: 36). Na visão do Financial Times (2015):

Os trabalhadores da Amazon não são escravos ... O Sr. Bezos está no mais obstinado limite do empreendedorismo dos EUA. Mas até que haja mais evidências de que sua abordagem esteja impedindo a equipe principal de integrar a Amazon, ou afastando os clientes, é improvável que ele mude - e parece haver pouca razão para que ele deva mudar.

Parece que o varejo, com seu sofisticado uso da tecnologia da informação como ferramenta de planejamento executivo e controle do trabalho, emergiu como uma força protagonista na administração, especialmente nas indústrias de serviços, afetando tanto o setor privado quanto o público.

\section{Trabalho estatal}

Apesar das privatizações em larga escala e da subcontratação, uma grande parte do setor de serviços permanece no setor estatal, onde encontramos alguns dos maiores empregadores ${ }^{13} \mathrm{da}$ UE e dos EUA. A natureza das relações de trabalho e emprego neste setor estatal é, portanto, interessante. Embora nunca tenha sido o centro da Sociologia do trabalho, o setor estatal, com seus altos índices de empregos sindicalizados e profissionalizados, continha exemplos em que 0 trabalho era organizado com um certo grau de liberdade do controle gerencial, muitas vezes ligado a uma ética do serviço público. Essa memória de trabalhar como carteiro nos anos 1970 no Reino Unido revela elementos de tudo isso:

Eu gostava de ser carteiro. Sempre que me perguntavam sobre meu emprego, tinha orgulho de fazer essa declaração. Eu sentia que havia um certo prestígio. Gostava do trabalho e da camaradagem com meus colegas. Sim, a remuneração básica era baixa, mas poderia ser complementada e eu gostava da sensação de segurança e de pertencer a uma instituição histórica. (Johnson, 2014: 125, ênfase no original)

Há muitos relatos semelhantes, todos apontando para o fato de que, ironicamente, foi o período pós-fordista que levou a forma de processo de trabalho fordista ao setor estatal sob os pretextos da produção enxuta e das novas formas

13 Quando a BBC tentou estabelecer uma lista dos maiores empregadores do mundo, sete dos dez principais eram de propriedade estatal! Nesta lista, o Walmart foi ofuscado pelo Departamento de Defesa dos EUA, com 3,2 milhões de empregados. O NHS britânico, com 1,7 milhão de funcionários, ficou em quinto lugar (BBC, 2012). 
de gestão do setor público, em grande parte tomadas de empréstimo de práticas das corporações privadas ${ }^{14}$. Parece que esse processo afetou tanto o serviço de rotina quanto as atividades profissionais de médicos, professores e afins. Geralmente a experiência é de maior pressão e coação.

No Reino Unido, o estudo de Foster e Hoggett (1999) de uma agência de seguridade social revelou como os trabalhadores ficavam angustiados ao se depararem dia após dia com pressões dos clientes, bem como com suas necessidades muitas vezes urgentes. Em vez de um processo de trabalho flexível, descreveram um "processo de trabalho exaustivo", mantido pelo compromisso com o serviço público. Essa extensão das técnicas de produção enxuta para o setor estatal foi demonstrada de forma mais nítida pelas investigações sobre as mudanças introduzidas nos escritórios de tributação do Departamento de Receitas e Alfândega do Reino Unido. Aqui, a maioria dos funcionários identificou a produção enxuta com uma mudança para um ambiente de trabalho com muita pressão. Um oficial administrativo do sexo feminino explica que:

Depois de vinte e sete anos na Receita Federal, acompanhando a introdução do trabalho enxuto, agora estou desqualificada, desmotivada, estressada durante mais dias, com medo de estar doente, sentir-me desvalorizada, prestar um serviço ruim para os clientes, não tenho permissão para expressar minha opinião, aguardo ansiosamente o dia em que eu possa deixar este lugar de uma vez por todas. (Carter et al., 2013: 762)

Tudo isso foi aliado a novos sistemas de informações gerenciais que se baseiam em sua capacidade de gerar grandes quantidades de dados comparativos de desempenho. Enquanto a Ford comparava a produção de suas diversas plantas fabris, bem como destas com os seus concorrentes, na década de 1980, hoje os hospitais e as universidades do Reino Unido veem-se regularmente inseridos em várias tabelas de classificação de desempenho e colocados em oposição uns aos outros através de vários arranjos de mercado (Beynon, 2016, McGettigan, 2013). Comentando essas questões de maneira mais geral, Monbiot (2014) observou que:

O local de trabalho tem sido sobrecarregado por uma infraestrutura kafkiana louca de avaliações, monitoramento, medição, vigilância e auditorias, direcionada centralmente e rigidamente planejada, cujo objetivo é premiar os vencedores e punir os perdedores. Destrói a autonomia, a empresa, a

14 A ironia adicional, é claro, é que Johnson se tornou um membro do governo que ajudou a impulsionar e estender essas mudanças. 
inovação e a lealdade e gera frustração, inveja e medo. Através de um magnífico paradoxo, levou ao renascimento de uma grande tradição soviética ... conhecida como tufta. Significa falsificação de estatísticas para satisfazer os ditames do poder inimputável.

A referência soviética se relaciona a visão inicialmente positiva de Lenin sobre o fordismo e sua capacidade de transformar a economia soviética. Também foi observado por Ron Amman, que descobriu que seu conhecimento das operações da antiga União Soviética, "longe de ser uma perda de tempo, tinha me proporcionado uma qualificação única” para uma compreensão das reformas do setor público no Reino Unido. Com alguma ironia, ele escreveu que "as crescentes pressões gerenciais sobre o setor público na Grã-Bretanha, que causaram consternação e incompreensão a muitos colegas, foram instantaneamente reconhecidas por uma antiga mão soviética" (Amman, 2003: 468).

\section{Tornando-se global}

O emprego estatal também está mudando de outras formas. Em 2011, o Gabinete do Governo do Reino Unido produziu uma Nota de Orientação que se concentrava em "situações em que os fornecedores de um serviço contratado desejariam usar a capacidade offshore para entregar alguns ou todos os serviços em questão" (www.sourcingfocus.com/site/ newsitem / 3829 /,) revelando até que ponto o estado havia emergido como coordenador da terceirização internacional. Essa mudança estava claramente ligada ao desenvolvimento de uma economia globalizada e teve um impacto direto sobre a organização e natureza do trabalho em relação à promessa.

Historicamente, a crise do fordismo se refletia em empresas crescentemente transferindo o trabalho para locais com baixos salários. Cowie, em seu principal estudo da RCA, viu isso como uma mudança radical em um padrão estabelecido na "luta contínua do capital industrial para manter as condições sociais necessárias para a lucratividade" (Cowie, 1999: 2). Isso foi facilitado, em grande parte, pelo advento do microprocessador e da internet que, junto com a comunicação via satélite, permitiram que máquinas e escritórios, em locais espacialmente separados, fossem interligados, e que equipes separadas de projeto e fabricação estivessem trabalhando em sistemas de produção distribuída. Desse modo, uma nova divisão internacional do trabalho começou a emergir, primeiro no vestuário, mas depois de forma mais geral (Barnet e Mueller, 1974; Froebel et al., 1981). Isso foi fortemente associado com os desenvolvimentos na indústria eletrônica, enquanto ocorria uma reestruturação indiscriminada na 
organização do emprego em todo o planeta. Na virada do século, a mudança incremental havia sido substituída pela ampla transferência de indústrias inteiras.

Isso pode ser visto como o surgimento de um fordismo global (Lipietz, 1982). Na Europa e nos Estados Unidos, isso foi associado a amplos fechamentos de fábricas, à medida que grandes centros de produção foram desmantelados (Bluestone et al., 1981; Massey; Megan, 1982) e novos foram abertos, inicialmente mais ao sul (na Espanha e no México), mas depois por todo o mundo, sendo que o principal impacto viria da China e da Índia. A indústria de diamantes é um exemplo. Por um século, o corte e o polimento dos diamantes do mundo foram baseados na Bélgica. Não mais: agora, 93\% desse trabalho é feito na Índia por 1,3 milhão de trabalhadores, embora esse processo de trabalho alterou-se de uma tal maneira que poderia ter saído das páginas do livro de Braverman. Cross (2014: 93), em seu estudo sobre o papel do gigante subcontratante Worldwide Diamonds, descreve isso como "a clássica história do nivelamento por baixo promovido pela globalização".

Em 2014, três empresas chinesas apareceram entre as dez principais empresas globais da Fortune, quando classificadas por receita (http://fortune.com/global50o/) e as 500 principais da Financial Times incluíram 23 empresas chinesas e 12 indianas ${ }^{15}$. Uma conseqüência disso foi vista na indústria automotiva do Reino Unido. Quando a MG Rover entrou em processo de insolvência em 2005, seus principais ativos foram adquiridos pelo Nanjiing Automobile Group, que foi adquirido pela estatal Shanghai Automotive Industry Corporation (SAIC). A SAIC é a maior dentre as "quatro maiores" montadoras de automóveis chinesa e estabeleceu um empreendimento conjunto com a Volkswagen e a General Motors, produzindo 4,5 milhões de carros por ano. O surgimento da indústria (e o uso extensivo de joint ventures) tem sido emblemático da transformação do país em um grande fabricante. Em 1990, a indústria automobilística estava operando em um nível baixo de desenvolvimento tecnológico, com 1,57 milhão de trabalhadores produzindo meio milhão de veículos. Em 2010, no entanto, mais de 18 milhões de veículos estavam sendo produzidos, mas com apenas um leve aumento da força de trabalho que passou para 2,2 milhões. Esses números oficiais, como Zhang (2014) explica, ocultam os empregados em contrato temporário. Na China, as empresas automobilísticas estabeleceram elementos fortes de um regime fordista, repleto de TQM e técnicas de produção enxuta, e com o apoio dos sindicatos ligados ao Estado. No entanto, os benefícios do sistema não foram distribuídos uniformemente para toda a força de trabalho. No momento em que o sistema de joint ventures se estabeleceu, Zhang explica que houve um movimento em direção a

15 Também inclui dez do Brasil, oito da Rússia e cinco do México (ft.com/indepth/ft500). 
um local de trabalho mais enxuto e flexível, incluindo a substituição de trabalhadores permanentes e de longo prazo por trabalhadores formais contratados, bem como o uso de uma força de trabalho dual e de um grande número de trabalhadores temporários. No início dos anos 2000, o regime trabalhista no setor de montagem de automóveis havia mudado para um regime de trabalho dual. (Zhang, 2014: 48)

O tratamento desigual dessas diferentes categorias de trabalhadores, combinado com o ritmo e a organização do trabalho, emergiu como uma fonte de tensão e conflito aberto, com os relatos em primeira mão de Zhang, ampliando nossa compreensão da crescente agitação trabalhista (Mitchell e Sebastopulo, 2014). Um padrão semelhante foi observado na Índia, onde a indústria automobilística, embora menos avançada do que sua equivalente na China, revela uma dependência similar de trabalhadores temporários cujos salários equivalem a pouco mais que um terço dos salários ganhos pelos funcionários permanentes (Annavajhula; Pratap, 2012; Cross, 2014). Um estudo de uma localidade em Uttar Pradesh, o estado com o mais alto nível de investimento estrangeiro direto em manufatura no país, descobriu que, embora a mistura de práticas variasse:

Os temas dominantes que surgiram foram empresas controlando trabalhadores por meio do uso de múltiplos contratos de trabalho, alta rotatividade de mão-de-obra, diferenças salariais, controle crescente sobre os regimes de trabalho, carga de trabalho intensa, desqualificação, contenção de sindicatos, uma atmosfera de medo em muitas empresas e controle através do uso de suportes institucionais. (Trivedi, 2007: 12)

Geralmente havia "um clima de medo em muitas empresas" (Trivedi, 2007: 12). Condições como estas foram identificadas como motivadoras de tumultos nas fábricas de automóveis da Îndia ano a ano, com vários deles resultando em assassinato de pessoal das equipes administrativas (Sarkar, 2015).

A indústria automobilística é apenas uma parte da imagem complexa do alcance global do capital. De fato, as raízes dessa expansão estão além do automóvel, no enorme desenvolvimento da comunicação eletrônica e das tecnologias digitais. Frequentemente associado pela opinião pública ao "Vale do Silício" na Califórnia, esse setor tem sua base produtiva em outros lugares. Os principais minerais (tântalo, estanho e ouro) são extraídos na República Democrática do Congo, muitas vezes sob condições de trabalho forçado (Fuchs, 2014), enquanto os laptops, tablets e telefones celulares são montados na China e no Pacífico. Aqui, a empresa taiwanesa Hon Hai Precision Industry (Foxconn) desempenha 
um papel de liderança. A maior empresa de manufatura privada do mundo, a Foxconn emprega 1,2 milhão de pessoas e, de suas fábricas na China, abastece a Apple, a Dell e a Hewlett Packard. Aqui o trabalho é organizado em regimes que beiram o "taylorismo sangrento" (Lipietz 1987, 1995, Jessop e Sum, 2006), com o uso extensivo do trabalho feminino migrante ${ }^{16}$. A principal instalação da empresa em Longhua emprega 400.000 trabalhadores, sendo a maioria jovens migrantes do interior. A fábrica opera 24 horas por dia, produzindo um quarto de milhão de iPhones nos 365 dias do ano. Os trabalhadores têm um dia de folga a cada quinzena. Nos outros dias eles passam 12 horas na fábrica. Uma jovem empregada como funcionária geral da linha de montagem (número funcional F9347140) descreveu seus dias desta maneira:

Eu era responsável pelas inspeções das telas de vidro para ver se elas estavam arranhadas. Eu me apresentava aos líderes da linha de 15 a 20 minutos antes da chamada. Os líderes nos devam palestras sobre como manter a alta produtividade, de modo a atingir metas diárias de produção e manter a disciplina. ... As pausas de toalete durante o horário de trabalho também são restritas. Eu tinha que pedir permissão aos assistentes dos líderes da linha para deixar o meu lugar.... Verificar as telas dos produtos fazia com que eu sentisse intensa dor nos olhos. (Chan, 2013)

Outra trabalhadora explicou como em seu trabalho:

Pego uma placa-mãe da linha, digitalizo o logotipo, coloco em uma bolsa anti-estática, coloco uma etiqueta e coloco na linha. Cada uma dessas tarefas leva dois segundos. A cada dez segundos, termino cinco tarefas. (Chan, 2013)

De modo a refletir os relatos das fábricas de Henry Ford do Rio Rouge, aprendemos que:

O bate-papo amigável entre colegas de trabalho não é muito comum mesmo durante o intervalo; todos correm para fazer fila para o almoço e comem

16 Lipietz (1995:) vê o "taylorismo sanguinário" como tendo dois componentes: "primeiro, as atividades são primariamente tayloristas, mas relativamente pouco mecanizadas. A composição técnica do capital nessas empresas é particularmente baixa. Desta forma, essa estratégia de industrialização evita um dos inconvenientes da substituição de importações: o custo de importar grandes quantidades de equipamentos. Além disso, dado que esta estratégia mobiliza uma força de trabalho feminina, ela incorpora todas as tradições da exploração patriarcal doméstica. Em segundo lugar, essa estratégia é "sangrenta" no sentido de que Marx falou de "legislação sangrenta” no início do capitalismo inglês. Para a opressão tradicional das mulheres, esta estratégia acrescenta todas as armas modernas da repressão anti-trabalho (sindicatos oficiais, ausência de direitos civis, prisão e tortura de opositores). 
rapidamente. A empresa proíbe conversas na oficina. Na área da fábrica, câmeras de CFTV estão instaladas praticamente em todos os lugares para fins de vigilância. Milhares de agentes de segurança estão de plantão, patrulhando todos os edifícios e dormitórios da fábrica da Foxconn. (Chan, 2013)

Também por outras vias os trabalhadores da linha de montagem da Foxconn estão predispostos a dizer que, "do lado de fora, todo mundo quer trabalhar aqui; do lado de dentro, todo mundo quer sair daqui". Em 2014, a Foxconn anunciou a abertura de novas fábricas na Turquia e na Eslováquia.

Essa mudança global para longe dos estados capitalistas avançados é fundamental para uma compreensão do estado de mudança do trabalho e de como as indústrias de serviço, especialmente na esfera das telecomunicações, foram afetadas de maneira igualmente radical. Nos estados da OCDE, especialmente no Reino Unido, os call centers passaram a ser vistos como uma fonte importante de inovação técnica, proporcionando o crescimento do emprego e compensando a perda de empregos na indústria. Esses locais se tornaram a principal fonte de comunicação rotineira do consumidor com as grandes corporações. Localizados principalmente nas antigas regiões desindustrializadas, eram frequentemente usados para simbolizar um novo amanhecer; um novo modo de vida e de trabalho. Em 2003, a indústria empregava quase 400.000 pessoas e as esperanças de uma expansão significativa chegavam a quase um milhão de empregados até o final da década. O futuro, no entanto, mostrou-se menos previsível e o crescimento mais instável. No entanto, ainda em 2013, a indústria do Reino Unido empregou 650,5 mil "agentes" em mais de 5 mil estabelecimentos. Muitos deles eram pequenos, mas mais da metade da força de trabalho era empregada nos 400 maiores deles. Nessa época, a indústria havia mudado de nomenclatura para call para contact centers, mais comumente associada a grandes corporações globais especializadas, trabalhando principalmente para os setores de varejo e finanças, sendo este (bancos, empresas de cartão de crédito, seguradoras, sociedades de crédito imobiliário, agências de cobrança e agências de referência de crédito) responsável por até 40 por cento do total das receitas ${ }^{17}$.

Os primeiros estudos do trabalho nesses centros se baseavam em outros paralelos com a manufatura, apontando para a natureza repetitiva do trabalho,

17 Esse desenvolvimento foi associado a uma reestruturação do sistema bancário da década de 1990 que transferiu a "agência bancária” do centro de operações. Escritórios especializados lidavam com a liquidação de contas enquanto as relações com os clientes e a comercialização de novos produtos eram tratadas através de call centers. Com esta divisão de trabalho mais especializada, podemos ver uma mudança radical no sistema de recrutamento, onde a nomeação de alunos que abandonaram a escola para uma "carreira com o banco" foi substituída por políticas de recrutamento multicamadas. 
bem como para as inerentes pressão e a vigilância gerencial. Os trabalhadores se referiam a isso como uma característica fundamental do trabalho, mencionando como "cada minuto era monitorado" e como "se recebiam dados estatísticos diários". Eles sabiam que suas conversas eram gravadas e que (cada vez mais) eram obrigados a manter um roteiro preparado:

Costumava ser mais um guia geral em vez de um roteiro. Tornou-se mais roteirizado agora. Agora eles estão dizendo "você precisa vender esses produtos neste pedido". (Beynon et al., 2001: 287)

Muitos pesquisadores (tendo como referência Hochschild) chegaram a ver isso como uma forma de trabalho emocional - conversando e lidando com as pessoas ao telefone; seguindo artificialmente um roteiro, embora parecesse "natural" e "genuíno" - e observou que as mulheres estavam sendo cada vez mais usadas nesses papéis (Belt et al., 2002; S. Taylor, 1998). Vários estudos têm apontado para as tensões associadas a essa forma altamente racionalizada de trabalho de comunicação (Deery et al., 2002; Holman, 2003) e de como explosões organizadas de "diversão" têm sido usadas para "liberar a pressão" nessas situações (Kinnie et al., 2000). Pois aqui as chamadas entram repetitivamente, assim que uma termina, a próxima começa, de um modo que traz à tona a metáfora da linha de montagem - "a linha de montagem na cabeça" é a frase sugerida por Taylor e Bain (1999). Assim como na manufatura, esse trabalho não era seguro nem imune ao crescente fenômeno do offshoring. Como a indústria britânica observou:

Esse setor mostrou a maior inclinação para se deslocar para o exterior, com muitas seguradoras (a Prudential e a Aviva são talvez as mais proeminentes) e bancos (Grupo Santander, Lloyds HBoS, Barclays e Barclaycard) aproveitando diferenciais de custos trabalhistas, embora outros bancos tal como o RBS não tenham feito o mesmo. Houve também um abalo, impulsionado pela crise de crédito, que colocou uma pressão maior sobre as empresas financeiras para reduzir ainda mais os custos. (Contato Babel, 2011)

Essas empresas receberam considerável apoio e incentivo de publicações como Off Shore Insights (2006), que explicava que:

Hoje, os benefícios das fontes globais incluem a capacidade de melhorar os níveis de serviço, novas oportunidades de crescimento e maior vantagem competitiva. Mas, mesmo que outros fatores de consideração se tornem determinantes para o sucesso de um país, na globalização a economia de custos continua sendo um elemento chave. $\mathrm{E}$, embora vários fatores afetem $\mathrm{o}$ 
potencial de redução de custos de qualquer acordo de fornecimento global, o custo da mão de obra está entre os mais importantes.

Este artigo inclui um mapa do mundo destacando possíveis centros de atendimento com detalhes sobre as médias salariais. Aqui, a Índia emergia como um local onde recrutas com alto-padrão educacional e bom inglês poderiam ser empregados para responder a consultas e vender produtos a clientes a cinco mil milhas de distância no Reino Unido e nos EUA. Isto foi apoiado pelo marketing forte do setor. O site https://www.outsource2india.com/ oferecia aconselhamento sobre a terceirização de serviços de hipotecas, edição de fotos, pesquisa e análise, desenvolvimento de software, serviços de engenharia, serviços de saúde, serviços financeiros e call centers. Tanto é que em 2012:

Existem mais de 265.000 empregos de $\mathrm{BPO}^{18}$ [Business Process Outsourcing] apenas em Bangalore, dos quais as posições de call center representam uma proporção considerável. O BPO é a palavra de ordem para a terceirização de processos de negócios - a tendência de empresas multinacionais como a Microsoft de alocar serviços ou departamentos inteiros na Índia. (Walker; Hatley, 2012)

A política de acolhimento da Índia para investimentos internos foi construída com base na fluência geral do inglês pela população, no elevado número de diplomados universitários e na no seu fuso horário. $\mathrm{O}$ trabalho noturno na Índia permitiu que os agentes entrassem em contato com cidadãos do Reino Unido e dos EUA ao longo do dia. Esse processo - trabalhando durante a noite e conversando com pessoas de uma cultura diferente em suas cozinhas e salas de estar, às vezes em um dia diferente do seu - adicionou uma nova dimensão ao trabalho emocional de se trabalhar em uma BPO (Bussiness Process Outsourcing). Também exigiu treinamento adicional, fornecido (a uma taxa de cerca de US \$ 900) por empresas como a Prion Edutech, que tem mais de cem campi de treinamento na Índia. Aqui, o objetivo principal é mudar a maneira como os agentes falam. Por exemplo, a erradicação da Influência da Língua Materna (ou abreviadamente MTI) é o foco do curso de 'Neutralização de Sotaque' de Prion. Aqui 'os alunos repetem sílabas como' pa pa pa pa pa 'por 30 minutos de cada vez até começarem a perder seu sotaque indiano' (Walker e Hatley, 2012). Uma vez empregado em um ambiente de BPO, falar Hindi é uma ofensa, para você trabalhar aqui, você precisa mudar quem você é.

18 BPO, em linhas gerais, trata-se de uma subdivisão de uma terceirização, onde um fornecedor de serviços terceirizados se responsabiliza por uma parte das tarefas que foi terceirizada à empresa contratante do serviço. 
Tanto em Delhi como em Bangalore todo mundo parecia ter histórias de seus antigos empregos, que eles chamavam de "processos" - "processos de cobrança", "processos de entrada" (atender chamadas), "processos de saída" (fazer ligações), - e todos eles se lembravam das ligações ruins.

Lembro-me muito bem desse cara que acabou de me ligar e disse do nada:

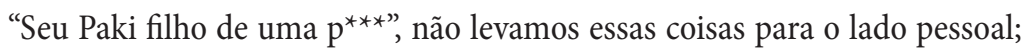
faz parte do trabalho. Então eu disse calmamente: "Sim, senhor, se eu sou um paquistanês, então este paki poderia lhe ajudar a consertar seu computador". (Marantz, 2011)

Geralmente, eles simplesmente passam por cima disso e seguem em frente. Como Sonam:

das 1 h as 11h todos os dias, ela se senta no chão com um fone de ouvido preso firmemente em torno de sua cabeça, o microfone preso na frente da boca com um arame rígido. Até 100 vezes por dia, um bipe soa em seu ouvido para avisá-la de que outro canadense precisa de ajuda com o seu banco. Ela não precisa aceitar ativamente a ligação; ele simplesmente entra em operação e as informações da conta aparecem na tela à sua frente.

"Olá, Sr. Smith, obrigado por ligar para o TD Canada Trust Bank, como posso ajudá-lo hoje?”

Quando o problema é resolvido ou a venda é finalizada ... outro bipe ressoa em seus fones de ouvido em menos de cinco segundos. ... Ela tem o poder de adiar o sinal sonoro, apertando um botão marcado como "AEW" no monitor, mas ela ri: 'Se eu suspender os telefonemas por mais de quinze segundos, eles [seus gerentes] virão atrás de mim.' (Walker; Hatley, 2012)

No entanto, houve problemas na Índia. As taxas de crescimento no emprego começaram a desacelerar, pois havia relatos de elevadas taxas de rotatividade girando em torno de 30\% a 35\% em locais estabelecidos (Vaidyanathan, 2011). Estes localizavam-se em grande parte nas cidades "de nível 1", e a transferência para longe dessas áreas mais prósperas tornou-se uma prioridade para as empresas. Cidades de nível 3, como Ahmedabad e Jaipur, ofereciam locais que eram visados, assim como estados vizinhos, como as Filipinas.

Várias empresas indianas iniciaram consideráveis operações nas Filipinas, que tem um grande grupo de graduados bem-educados, falantes de inglês, talentosos e empregáveis. Quase 30\% dos diplomados nas Filipinas são 
empregáveis, ao contrário dos $10 \%$ da Índia, onde o treinamento consome uma quantidade considerável de tempo, de acordo com o relatório. (Press Trust of India, 2014)

O secretário-geral da Assocham (Associação de Câmaras de Comércio e Indústria da Índia) falou dos temores de que o país possa perder até US \$ 30 bilhões em ganhos cambiais para as Filipinas e que "há uma necessidade de reduzir custos e fazer operações mais enxutas na indústria de BPO” (Press Trust of India, 2014).

Ao mesmo tempo, há uma pressão competitiva da Europa Oriental, à medida que as empresas britânicas começaram a terceirizar partes de seus serviços ao consumidor para empresas sediadas na Bulgária. A 6oK é uma dessas empresas, empregando 650 funcionários que falam 27 línguas diferentes entre eles. A $60 \mathrm{~K}$ foi eleita a "terceirizada do ano" na cerimônia do European Call Center e Customer Service Awards em 2013 e seu CEO, Jonathan Gladwish, explicou como se economiza de 40 a 50 por cento se mudando do Reino Unido, onde trabalhar em um call center é muitas vezes visto como meramente um "paliativo" para os graduados (Merrill, 2013). Embora tenha havido rumores acerca do retorno dos trabalhos de call center ao Reino Unido (ContactBabel, 2011; Arvato, 2015), esse processo ainda é incerto. $\mathrm{O}$ que está claro é que essa indústria, assim como a manufatura, "se tornou global" - com sua falta de raízes em conjunção a uma forte lógica de redução de custos: como Marantz, (2011) observou com precisão, até mesmo os vencedores são perdedores em algum grau porque:

Os agentes sabem que seus empregos só existem por causa do baixo valor que o mercado mundial atribui ao (seu) trabalho. Quanto mais eles adotam a lógica do capitalismo global, mais eles precisam confrontar a noção de que valem menos.

\section{Tempos digitais: 0 ciberproletariado, o precariado e o povo}

Ao refletir sobre as mudanças ocorridas nos últimos quarenta anos, sociólogos do trabalho tiveram que adotar uma visão mais ampla e reflexiva, que fosse além do próprio local de trabalho, à medida que os mercados nacionais se fragmentaram, os sistemas de produção e comunicação se tornaram globais e as políticas econômicas keynesianas foram substituídas por políticas neoliberais. Dentro de tudo isso, uma revolução tecnológica ocorreu associada ao desenvolvimentos extraordinários na computação. Esta revolução viu o cumprimento da "Lei de Moore" que dizia que o poder de computação 
dobraria a cada dois anos. O Playstation 3 da Sony fornece um bom exemplo disso. Lançado em 2006, ele tinha o poder de computação do poderoso computador ASCI Red, que custou US \$ 55 milhões ao governo americano em 1996 e ocupou 100 gabinetes de mais de 1.600 metros quadrados de espaço. Brynjolfsson e McAfee (2014) usam esse exemplo para destacar as implicações do crescimento exponencial à medida que nos aproximamos da "Segunda Era da Máquina" associada à "digitalização de praticamente tudo". Aqui e em outros lugares (2011) sua admiração pela capacidade das novas máquinas é acompanhada por preocupações sobre seu impacto social, sobretudo no tocante aos empregos, com o ressurgimento do interesse na noção de "desemprego tecnológico" de Keynes. Uma análise abrangente em um workshop sobre Máquinas e Emprego na Universidade de Oxford concluiu que esses desenvolvimentos, diretamente ou por meio de offshoring, "colocarão uma parte substancial do emprego, numa vasta gama de ocupações, em risco num futuro próximo" (Frey; Osborne, 2013).

O ritmo dessas mudanças levou Huws (2013) e outros a verem as primeiras décadas do século XXI como representando um novo ponto de partida na escala da divisão internacional do trabalho. Standing (2009) concorda e, assim como Munck (2002), traçou paralelos com as mudanças do século XIX descritas por Polanyi em The Great Transformation (1944), quando a mercantilização do trabalho foi levada ao extremo e o trabalho se desligou das instituições sociais. Nessa visão, a segunda grande transformação é um fenômeno global, com 1,5 bilhão de pessoas competindo por empregos altamente flexíveis, muitos deles como "trabalhadores contingentes e temporários de diversos gêneros", compondo um grupo que Standing descreve como "o precariado" (ILO, 2014, Standing, 2009, 2011: 110). Vimos exemplos desse processo na China e na Índia, com trabalhadores rurais migrando para centros urbanos, competindo por trabalho.

Este tema foi desenvolvido por Roberts (2004) quando escreveu sobre "serviços na linha de montagem”, e Huws $(2003,2014)$ também escreveu extensivamente sobre as maneiras pelas quais a vida dos "trabalhadores do teclado" foram afetadas pelas mudanças na computação e no processamento de texto. Ela argumenta que o "taylorismo digital" ultrapassou o relato de Braverman sobre a mudança no trabalho de escritório, e vê o surgimento de um cyberproletariado no centro das mudanças contemporâneas no trabalho. Essa ideia decorre em parte das maneiras pelas quais as plataformas digitais permitiram que poderosas corporações transnacionais estendessem suas estratégias de terceirização para trabalhadores individuais localizados em todo o mundo. Os expoentes 
bem conhecidos deste chamado crowd work ${ }^{19}$ seriam CrowdFlower, Clickworker e CloudCrowd. A CloudFlower anuncia sua "mão-de-obra sob demanda" como solução, fornecida por mais de 500.000 funcionários em mais de 70 países:

Os clientes da CrowdFlower concluem rapidamente volumes maciços de trabalhos simples, sem nenhum tempo de espera e custos indiretos associados à contratação e à terceirização tradicionais. (Disponível em: $<\mathrm{http}: / /$ www.crowdsourcing.org/site/crowdflower/crowdflowercom/1572>. Acesso em: 11 set. 2019.)

Mais uma vez, foi a Amazon, por meio de sua operação conhecida como Mechanical Turk, que ampliou os horizontes. 0 mechanical turk tem sua própria linguagem mistificadora na qual os empregadores são chamados de "Solicitantes"; os trabalhos, "Tarefas de Inteligência Humana" ou "HITs"; e os trabalhadores, "Provedores" ou "Turkers". Na realidade, a forma como o trabalho é organizado equivale a uma reencarnação do sistema doméstico de trabalho, em que os trabalhadores executam parcelas do processo de trabalho delineadas pelos empregadores (ou por programas de computador preparados para extrair trabalho em favor dos empregadores), pelas quais são pagos por peça, ofertadas na plataforma da Amazon, com a Amazon cobrando do empregador 10\% de comissão. O site Mechanical Turk da Amazon promete uma "força de trabalho sob demanda e flexível na nuvem" e a capacidade de "acessar milhares de trabalhadores sob demanda de alta qualidade e baixo custo" (Amazon Mechanical Turk, 2015). O trabalho assume a forma de micro tarefas, que os computadores não podem fazer ou não executam tão bem quanto os humanos. Exemplos que a própria Amazon fornece incluem, entre outros: processamento de foto e vídeo (por exemplo, marcação de objetos encontrados em uma imagem para facilitar a busca, encontrar a melhor imagem para representar um produto); verificação de dados (eliminação de entradas duplicadas nas páginas amarelas); coleta de informações (encontrar campos específicos ou elementos de dados em grandes documentos legais ou governamentais); e processamento de dados (tradução, avaliação da precisão dos resultados de um mecanismo de pesquisa). A tarefa pode ter valor em si mesma. Por exemplo, quando usado em conjunto com um iPhone, os trabalhadores da Mechanical Turk podem ajudar pessoas cegas a

19 Nota do tradutor: Crowd work ou crowdsourcing envolve um grande número de pessoas, geralmente conectadas a plataformas digitais, que trabalham na resolução de algum problema. Vale destacar o processo de trabalho aqui é realizado de modo compartilhado por pessoas localizadas em diferentes lugares. Para mais informações vide: http://infograficos.estadao.com.br/focas-economicos-13/crowdsourcing.shtml 
encontrar objetos específicos, sejam eles frascos de marmelada, chaves de casa ou qualquer outra coisa, e 'ler', digamos, nomes de ruas (Jabr, 2011). Esses tipos de trabalho são excepcionais, no entanto. Normalmente, as tarefas taylorizadas são fragmentos de um processo maior que, muitas vezes, têm que ser concluídas de uma maneira altamente repetitiva (Bergvall-Kareborn e Howcroft, 2014).

O pagamento pelo crowd work é geralmente baixo, estimado em US \$2 por hora (Marvit, 2014) e podendo ser altamente estressante. Neste trabalho, um fluxo constante de HITs não podem confiar em seus contratos, nem contar com preços constantes, nem mesmo ter a certeza de que os empregadores, que têm o chicote, pagarão pelo trabalho realizado. Tudo isso contribui para os níveis de estresse que se tornam ainda mais agudos se o "turking" for uma fonte primária de renda. Esses trabalhadores, que passam horas realizando pequenas tarefas e procurando trabalhos adicionais para executar, o fazem separados uns dos outros, existindo em um limbo legal. É uma força de trabalho cada vez mais dispersa, com uma proporção crescente composta de trabalhadores indianos, mais propensos a ter menos instrução e forçados a depender do trabalho on-line como principal fonte de renda (Ipeirotis, 2010; Ross et al., 2010). Seu tamanho é difícil de estimar com precisão, mas Kaganer et al. (2012) descrevem um "crescimento anual vertiginoso" na receita global de plataformas de crowdsourcing, que aumentaram $53 \%$ em 2010 e $74 \%$ em 2011. Em uma pesquisa geral, Mandl (2015) indicou que há um potencial significativo de crescimento desta forma de emprego em toda a Europa.

Este novo sistema de pagamento por produção digitalizada é muitas vezes apresentado como um sistema no qual os talhadores realizam "escolhas". A principal atração para os empregadores desse novo taylorismo é que ele é uma fonte de força de trabalho barata e altamente explorável. O crowd work oferece um sistema barato, cada vez mais global e de "zero hora", que, como tal, sintetiza o subemprego que caracteriza grande parte do mundo do trabalho atualmente.

O crowdsourcing não se restringiu ao registro de dados e ao trabalho rotineiro de escritório. Foi estendido aos trabalhos inovadores que eram para constituir o próprio cerne da revolução criativa do trabalho trazida pela tecnologia da informação. Ao olhar para o desenvolvimento e criação de software, por exemplo, Baldry e Marks (2009) passaram a ver esse tipo de trabalho de conhecimento como "manufatura de colarinho branco". Na área de aplicativos móveis, a Apple e o Google, líderes de mercado, conseguiram, por meio do crowdsourcing, terceirizar essa atividade de desenvolvimento, aproveitando a criatividade de desenvolvedores individuais em todo o mundo. Ocupando uma posição entre empregado casual e empreendedor, esses designers têm uma vida profissional 
com base no domicílio, o que acentua as tendências atuais na nova economia além do fordismo. No entanto, também "aumenta ainda mais a precariedade e a incerteza” (Bergvall-Kareborn e Howcroft, 2013: 978).

Ao considerar esses desenvolvimentos, somos lembrados por Robert McChesney, autor de Digital Disconnect, que, a Internet começou como uma função do setor público, foi assistida por subsídios do governo e não foi comercial. A visão era "de um setor igualitário e sem fins lucrativos, onde as pessoas se reuniam e compartilhavam" (McChesney, 2014). Foi com esse espírito que o Linux foi iniciado no início dos anos de 1990 por Linus Torvalds, um estudante de pós-graduação em ciência da computação de 20 anos da Universidade de Helsinque. Esse sistema operacional livre e de código aberto foi desenvolvido sob uma licença que permitia o uso do software e possibilitava que os usuários o alterassem, compartilhassem e desenvolvessem como uma alternativa aos sistemas operacionais das grandes potências capitalistas, Microsoft e Apple. Como tal, o Linux representa o potencial para um estilo de vida sem fins lucrativos. Existem outros exemplos - a Wikipedia, uma plataforma colaborativa de escrita e informação de código aberto, o OpenStreetMaps, um projeto não comercial e colaborativo para criar e utilizar dados de mapas em todo o mundo; WordPress, software web gratuito para criação de sites e blogs; Drupal, uma estrutura de gerenciamento de conteúdo de código aberto com muitos acréscimos gratuitos à comunidade; GoTeo, uma rede social para crowdfunding 20 e colaboração; e $P_{2} P U$, uma universidade peer to peer, resumida pelo convite "Aprenda tudo com seus colegas. Está on-line e totalmente livre".

Estes são desenvolvimentos importantes e que sugerem o potencial de uma forma paralela e colaborativa de trabalho que emerge ao lado do mundo corporativo do neo-fordismo. Os trabalhadores do crowd work podem trabalhar coletivamente apesar da tecnologia digital. Turkoptican, é um complemento da plataforma da Mechanical Turk que permite aos trabalhadores divulgar e avaliar suas relações com os empregadores, classificando sua experiência, incluindo casos de não pagamento por parte dos empregadores pelo trabalho realizado. Existem fóruns on-line onde o trabalho pode ser discutido. Nos Estados Unidos, os trabalhadores do crowd work estão tentando fortalecer sua frágil posição em relação ao mercado de trabalho ao serem legalmente reconhecidos como empregados ao invés de empreiteiros, uma categoria que os exclui dos benefícios e provisões para os quais apenas empregados são elegíveis. Aqui também os

20 Trata-se de um financiamento coletivo, que muitas vezes é viabilizado por meio de plataformas colaborativas. 
estudiosos, comprometidos com as ideias originais da internet, consideraram maneiras pelas quais o mundo turk da Amazon poderia ser democratizado, com o desenvolvimento criativo e o empoderamento dos trabalhadores do crowd work. Após uma conferência sobre "crowd work", eles se reuniram para produzir um relatório que tentava planejar com antecedência, explicando que:

O crowdwork pode acontecer na escala de minutos, mas o impacto do crowdwork pode ser sentido por gerações. Perguntamos: o que será necessário para nós, as partes interessadas no crowdwork - incluindo solicitantes, trabalhadores, pesquisadores - sentirmo-nos orgulhosos de nossos próprios filhos quando estes passarem a compor tal força de trabalho? Responder a esta questão levou a uma discussão sobre o crowd work a partir de uma perspectiva de longo prazo. (Kittur et al.)

De um modo mais geral, os estudiosos apontam para o surgimento do trabalho colaborativo via internet e como isso estimulou o crescimento de uma nova compreensão do "povo". Bauwens (2013) identificou o surgimento de uma nova "classe trabalhadora cognitiva", cuja localização estrutural no trabalho de serviço ou cognitivo os inclina para os valores de abertura associados aos arranjos par-a-par (p2p). Tomando emprestado o relato de Marx sobre a transição do feudalismo para o capitalismo, ele vê o p2p como um proto-modo de produção:

em que o valor é criado por públicos produtivos ou "produtores" de inovações compartilhadas, sejam elas de conhecimento, código ou design. Isso ocorre onde as pessoas podem se ligar horizontalmente e sem necessidade de permissão a fim de criar valor comum conjuntamente. (Bauwern, 2012)

Apesar dos óbvios problemas colocados pelo poder das grandes plataformas corporativas, dos sistemas de segurança do estado e das formas como o Linux foi incorporado, Bauwens é otimista sobre o futuro dessa revolução silenciosa e a capacidade dessa nova classe trabalhadora de criar um espaço decisivo de atividade do povo dentro do mundo capitalista, assumindo o controle de seu trabalho.

\section{Conclusão: a visão a longo prazo}

A racionalização dos processos de produção e a extensão das divisões de trabalho possibilitadas pela produção de máquinas cada vez mais sofisticadas são claramente visíveis nas fábricas manufatureiras em todo o mundo. Mais significativo talvez fora a extensão desses princípios ao escritório e a uma ampla 
gama de indústrias de serviços, aceleradas pelas TIC e pela revolução digital. Ao avaliar as implicações desses desenvolvimentos, é difícil encontrar amplo apoio para as visões otimistas expressas nos anos de 1980. Embora ocorrera uma mudança significativa no estilo de gestão, notadamente com a ênfase no trabalho em equipe, a evidência para uma grande mudança nos sistemas de valores das grandes corporações, como sugerido por Boltanski e Chiapello (2002), é incipiente na melhor das hipóteses. Pelo contrário, as revisões mais recentes sobre as mudanças do mundo do trabalho e do emprego (Brown et al., 2012; Head, 2014; Urry, 2014) enfatizam as maneiras pelas quais as novas tecnologias facilitam as estratégias off-shoring a fim de manter as margens de lucro com base em trabalhos flexíveis de baixa qualificação. Na verdade, Urry começa seu relato com uma citação de Warren Buffett, o bem-sucedido investidor norte-americano, afirmando que: "há uma guerra de classes, mas é minha classe, a classe rica, que está fazendo guerra e estamos vencendo" ${ }^{21}$. (Urry, 2014: 1).

Ficamos com a questão de quão longe nos afastamos daquelas primeiras ideias de regimes de trabalho mais democráticos e satisfatórios. Certamente, se observadas do ponto de vista da autonomia do trabalhador e da proeminência de uma vida profissional baseada em tarefas de trabalho tensas e repetitivas, a resposta deve ser "não muito longe". Aqui é a extensão das práticas fordistas além da manufatura e além dos EUA e da Europa o que torna isso mais notável, lembrando-nos que o fordismo, mesmo sob Henry Ford, era mais adaptável do que se compreendeu recentemente (ver Clarke, 1992; Williams et al., 1992). Olhando para além do processo de trabalho, no entanto, houve mudanças significativas, principalmente na prática corporativa de terceirizar o trabalho anteriormente realizado "em casa". Essa ressurreição do subcontrato como parte central dos negócios aliou-se ao enfraquecimento dos contratos de trabalho por meio de diversos sistemas de agência, tornando muitos empregos temporários e tornando mais inseguro o trabalho. Essas tendências foram exacerbadas pelo uso de uma tecnologia da informação cada vez mais poderosa.

Essas são tendências globais e quando pensadas em escala mundial serão o novo foco da sociologia do trabalho, visto que os gestores se esforçam para imaginar e criar um mundo no qual "todas as ineficiências na produção sejam eliminadas" (Cross, 2014: 101) e os trabalhadores continuam buscando maior justiça e autonomia a partir de conversas sobre outros tipos de utopias reais (Wright, 2010).

21 Em outro momento, Buffett apontou a injustiça do fato de que ele, um bilionário, pagou menos impostos do que sua equipe de escritório rotineira. 


\section{Referências}

AMAZON MECHANICAL TURK. 2015. Disponível em: <https://www.mturk.com/ mturk/help?helpPage=overview. Acesso em: 12 set. 2019.

AMMAN, Ron. 'A Sociological View of Modern Britain'. The Political Quarterly, 2003, pp. 468-48o.

ANNAVAJHULA, J. C. Bose; PRATAP, Surendra. 'Worker Voices in an Auto Production Chain: Notes from the Pits of a Low Road - I and II', Economic and Political Weekly, 2012, XLVII.

ARVATO. Outsourcing Index. 2015. Disponível em: <http://www.arvato.co.uk/outsourcing-index>. Acesso em: 12 set. 2019.

BADRINATH, M. N.; SANTOSH KUMAR, Alakunta V.; DINESH, Nandan. 'Labor Dissonance at Maruti Suzuki India Limited: A Case Study on Industrial Relations', Global Research Analysis, v. 1, n. 5, 2012, pp. 72-74.

BALDRY, C.; MARKS, Abigail. 'Stuck in the Middle with Who? The Class Identity of Knowledge Workers', Work, Employment and Society, v. 23, n. 1, 2009, pp. 49-65.

BARKER, J. 'Tightening the Iron Cage: Concertive Control in Self-managing Teams', Administrative Science Quarterly, 38: 1993, pp. 408-437.

BARNET, Ronald J.; MUELLER, Richard E. Global Reach. New York: Simon and Schuster, 1974.

BASTRANI, N. (2016) We Want Everything, London, Verso, first published 1971, BAUWENS, M. (2009) 'Class and Capital in Peer Production' Capital and Class, v. 33, n. 1, pp. 121-141.

BAUWENS, Michel. 'Peer-to-Peer Production and the Coming of the Commons', Red Pepper, July, 2012.

BAUWENS, Michel. 'Thesis on Digital Labour in an Emerging P2P Economy'. 2013. In: T. Scholz (ed.) Digital Labor: The Internet as Playground and Factory. London: Routledge.

BBC. 'Which is the World's Biggest Employer?', 20 March, 2012. Disponível em: www. bbc.co.uk/news/magazine-17429786. Acesso em: 12 set. 2019.

BELT, Vicki; RICHARDSON, Ranald; WEBSTER, Juliet. 'Women, Social Skill and Interactive Service Work, 2002. In: Telephone Call Centres', New Technology, Work and Employment, v. 17, n. 1, pp. 20-34.

BERGVALL-KÅREBORN, Birgitta; HOWCROFT, Debra. 'The Apple Business Model: Crowdsourcing Mobile Applications', Accounting Forum, v. 37, n. 4, 2013, pp. $280-289$. BERGVALL-KÅREBORN, Birgitta; HOWCROFT, Debra. 'Amazon Mechanical Turk and the Commodification of Labour' New Technology, Work and Employment, v. 29, n. 3, 2014, pp. 213-223. 
BERNHARDT, Arnnette; MORRIS, Martina; HANDCOCK, Mark S.; SCOTT, Marc A. Divergent Paths: Economic Mobility, 2001. In: The New American Labor Market. New York: Russell Sage Foundation. BEYNON, Huw. Working For Ford. Harmondsworth: Penguin, 1973.

BEYNON, Huw. Working For Ford, 2nd edition. Harmondsworth: Penguin, 1985.

Disponível em: <http://huwbeynon.com/publications/>. Acesso em: 12 set. 2019.

BEYNON, Huw. 'The End of the Industrial Worker'. 1992. In: ABERCROMBIE, Nicholas; WARDE, Alan. (eds) Social Change in Contemporary Britain. Cambridge: Polity Press. Disponível em: <http://huwbeynon.com/research-themes/>. Acesso em: 12 set. 2019. BEYNON, Huw. 'Globalisation, Trade Union Organisation and Workers' Rights', 2003. In: FAIRBROTHER, Peter; YATES, Charlotte (eds) Trade Unions in Renewal: A Comparative Study. London: Continuum, pp. 263-281. Disponível em: $<$ http://huwbeynon.com/research-themes/>. Acesso em: 12 set. 2019.

BEYNON, Huw. "The Rise of the Corporate University in the UK" Global Dialogue: Magazine of the International Sociological Association, v. 6, n. 3, 2016.

BEYNON, Huw; GRIMSHAW, Damian, RUBERY, Jill; WARD, Kevin. Managing Employment Change. Oxford: Oxford University Press, 2001.

BLUESTONE, B.; HARRISON, B.; BARKER, L. Corporate Flight: The Causes and Consequences of Economic Dislocation. New York: The Progressive Alliance, 1981. BOLTANSKI, Luc; CHIAPELLO, Eve. The New Spirit of Capitalism. London: Verso, 2002. BRAVERMAN, Harry. Labour and Monopoly Capitalism: The Degradation of Work in the Twentieth Century. New York: Monthly Review Press, 1974.

BRENNER, Robert. The Economics of Global Turbulence: The Advanced Capitalist Economies from Long Boom to Long Downturn. London and New York: Verso, 2006. BRENNER, Robert; GLICK, Mark. 'The Regulationist Approach: Theory and History', New Left Review, v. 1, n. 188, July-August, 1991.

BROWN, Phillip; LAUDER, Hugh; ASHTON, David. The Global Auction: The Broken Promises of Education, Jobs and Incomes. Oxford: Oxford University Press, 2012. BRYNJOLFSSON, Erick; MCAFEE, Andrew. Race Against the Machine. Lexington, MA: Digital Frontier Press, 2011.

BRYNJOLFSSON, Erick; MCAFEE, Andrew. The Second Machine Age: Work, Progress and Prosperity in a Time of Brilliant Technologies. New York: W.W. Norton \& Company Inc, 2014.

BURAWOY, Michael. 'Public Sociology: Populist Fad or Path to Renewal?', British Journal of Sociology, v. 56, n. 3, 2005, pp. 417-432.

CADWALLADR, Carole. 'My Week as an Amazon Insider'. The Observer: Review, 1 December, 2013. Disponível em: <http://www.theguardian.com/technology/2013/ 
dec/o1/week-amazon-insider-feature-treatment-employees-work>. Acesso em: 12 set. 2019.

CARTER, Bob. 'Restructuring State Employment: Labour and Non-Labour in the Capitalists State', Capital and Class, 63, 1997, pp. 65-84.

CARTER, Bob; DANFORD, Andy; HOWCROFT, Debra; RICHARDSON, Helen; SMITH, Andrew; TAYLOR, Phill. "All They Lack is a Chain”: Lean and the New Performance Management in the British Civil Service', New Technology, Work and Employment, v. 26, n. 2, 2011, pp. 83-97.

CARTER, Bob; DANFORD, Andy; HOWCROFT, Debra; RICHARDSON, Helen; SMITH, Andrew; TAYLOR, Phill. 2013. "Stressed Out of My Box": Employee Experience of Lean Working and Occupational Ill Health in Clerical Work. In: The UK Public Sector', Work Employment and Society, v. 27, n. 5, pp. 747-768.

CHAN, J. 'A Suicide Survivor: The Life of a Chinese Migrant Worker at Foxconn', Asia Pacific Journal, v. 11, n. 31, n. 1, August 12, 2013.

CLARKE Simon. 'What in the Name of $F^{\star * \star}$ is Fordism' 1992. In: GILBERT, Nigel; BURROWS, Roger; POLLERT, Anna. (eds) Fordism and Flexibility. London: Macmillan Press.

COATES, Ken; TOPHAM, Tony. (eds). Workers' Control. London, McKibbon and Key, 1968. CONTACTBABEL. UK Contact Centres in 2012: The State of the Industry. 2011. Disponível em: <http://www.contactbabel.com/pdfs/dec2011/Marketing_UK_Contact_ Centres_in_2012_The_State_of_the_Industry.pdf >. Acesso em: 12 set. 2019.

CONTI, Robert; WARNER, Malcolm. 'Taylorism, New Technology and Just. 1993. In: Time Systems in Japanese Manufacturing', New Technology, Work and Employment, v. 5, n. 1, pp. 31-42.

COWIE, Jefferson. Capital Moves: RCA's Seventy Year Quest for Cheap Labor. Ithaca, NY: Cornell University Press, 1999.

CROSS, Jamie. Dream Zones: Anticipating Capitalism and Development in India. London: Pluto Press, 2014.

DEERY, Stephen; IVERSON, Roderick; WALSH, Janet. 'Work Relationships in Telephone Call Centres: Understanding Emotional Exhaustion and Employee Withdrawal, Journal of Management Studies, v. 39, n. 4, 2002, pp. 471-496.

DELBRIDGE, Rick. Life on the Line in Contemporary Manufacturing: The Workplace Experience of Lean Production and the 'Japanese Model'. Oxford: Clarendon Press, 1997.

DORAY, Bernard. From Taylorism to Fordism: A Rational Madness. London: Free Association Books, 1988.

DU GAY, Paul. “Numbers and Souls”: Retailing and De-Differentiation of Economy and Culture', British Journal of Sociology, v. 44, n. 4, 1993, pp. 563-587. 
EDWARDS, Richards. Contested Terrain: The Transformation of the Workplace in the Twentieth Century. London: Heinemann, 1979 (276).

EHRENREICH, Barbara. Nickel and Dimed: On (Not) Getting By in the USA. New York: Metropolitan Books, 2001 (256).

ELGER, Tony; SMITH, Chris. (eds) Global Japanization? The Transnational Transformation of the Labour Process. London and New York: Routledge, 1994.

FINANCIAL TIMES. "Noone is forced to work in the Amazon jungle", 17 August, 2015. Disponível em: <http://www.ft.com/cms $>$. Acesso em: 12 set. 2019.

FLORIDA, Richard; KENNY, Martin. 'Transplanted Organisations: the transfer of Japanese industrial organisation to the US' American Sociological Review 56, 1991, pp. 381-398

FOSTER, Deborah Jane; HOGGETT, Paul. 'Changes in the Benefits Agency: Empowering the Exhausted Worker?', Work Employment and Society, v. 13, n. 1, 1999, pp. 19-39.

FREY, Carl Benedikt; OSBORNE, Michael A. 'The Future of Employment: How Susceptible are Jobs to Computerisation?', 2013. Disponível em: <http://www. oxfordmartin.ox.ac.uk/downloads/academic/The_Future_of_Employment.pdf $>$. Acesso em: 12 set. 2019.

FRIEDMAN, Thomas L. The Lexus and the Olive Tree. New York: Anchor Books, 2000. FROBEL, Folker; HEINRICHS, Jurgen; KREYE, Otto. The New International Division of Labour: Structural Unemployment in Industrialised Counties and Industrialisation in Developing Countries. Cambridge: Cambridge University Press, 1981.

FUCHS, Christian. Digital Labour and Karl Marx. New York: Routledge, 2014.

GALLIE, Duncan, WHITE, Michael, CHENY, Yuan; TOMLINSON, Mark. Restructuring the Employment Relationship, Oxford: Clarendon Press, 1998.

GLYN, Andrew. 'Productivity and the Crisis of Fordism', International Review of Applied Economics, 4, 1990, pp. 28-44.

GLYN, Andrew; SUTCLIFFE, Robert. British Capitalism, Workers and the Profits Squeeze. London: Penguin, 1972.

GOOS, Maarten; MANNING, Alan. 'Lousy and Lovely Jobs: The Rising Polarization of Work in Britain', Review of Economics and Statistics, v. 89, n. 1, 2007, pp. 118-133.

GRAHAM, Laurie. On the Line at Subaru-Isuzu: The Japanese Model and the American Worker, Ithaca: Cornell University Press, 1994a.

GRAHAM, L. 'How Does the Japanese Model Transfer to the United States? A View from the Line'. 1994b. In: ELGER, Tony; SMITH, Chris. (eds) Global Japanisation? The Transnational Transformation of the Labour Process. London: Routledge. GRAMSCI, Antonio. Prison Notebooks. London: Lawrence and Wishart, 1971. GRIMSHAW, D., BEYNON, H., RUBERY, J.; WARD, K. 'The Restructuring of Career Paths in Large Service-Sector Organisations: "Delayerting", Upskilling and Polarisation', Sociological Review, v. 50, n. 1, 2002, pp, 89-116. 
HAMPER, B. Rivethead. New York: Warner Books, 1986.

HARVEY, Mark; QUILLEY, Stephen; BEYNON, Huw. Exploring the Tomato: Transformations of Nature, Society and Economy. Cheltenham: Edward Elgar, 2002.

HEAD, Simon. Mindless: Why Smarter Machines Are Making Dumber Humans. New York: Basic Books, 2014.

HEROUVIM, J. 'Post Fordism and Pragmatic Politics', Meanjin, v. 48, n. 3, 1989, pp. 583-590.

HOLMAN, David. 'Phoning In Sick? An Overview of Employee Stress in Call Centres', Leadership and Organization Development Journal, v. 24, n. 3, 2003, pp. 123-130.

HUDSON, R. 'Labour Market Changes and New Forms of Work in Old Industrial Regions: Maybe Flexibility for Some but Not Flexible Accumulation', Environment and Planning D: Society and Space, v. 7, n. 1, 1989, pp. 5-30.

HUWS, Ursula. The Making of a Cybertariat: Virtual Work in a Real World. New York: Monthly Review Press, 2003.

HUWS, Ursula. 'The Underpinnings of Class in the Digital Age, Living, Labour and Value'. 2013. In: PANICH, Leo; ALBO, Greg; CHIBBER, Vivek. (eds) Registering Class, Socialist Register 2014. London: The Merlin Press, pp. 80-107.

HUWS, Ursula. Labour in the Global Digital Economy: The Cybertariat Comes of Age. New York: Monthly Review Press, 2014.

HUYS, Rik; SELS, Luc; VAN HOOTEGEM, Geert; BUNDERVOET, Jan; HENDERICKX, Erick. 'Toward Less Division of Labor? New Production Concepts in the Automotive, Chemical, Clothing and Machine Tool Industries', Human Relations, v. 52, n. 1, 1999, pp. 67-93.

ILO. World Work Report. Geneva: International Labour Organization, 2014.

IPEIROTIS, P.G. (2010) 'Demographics of Mechnaical Turk', CeDER Working Papers, Stern School of Business. Available at https://archive.nyu.edu/handle/2451/29585 (accessed 15 September 2014).

JABR, F. (2011) 'Phone App Lets Blind See Through Crowd's Eyes'. Available at https://www. newscientist.com/blogs/onepercent/2011/05/smartphone-app-lets-the-blind.html JESSOP, Bob. State Theory: Placing the Capitalist State in Its Place. London: Polity, 1991. JESSOP, Bob; SUM, Ngai-Ling. Beyond the Regulation Approach: Putting Capitalist Economies in their Place. Cheltenham: Edward Elgar, 2006.

JOHNSON, Alan. Please, Mister Postman: A Memoir. London: Bantam Press, 2014. KAGANER, Evgeny; CARMEL, Erran; HIRSCHHEIM, Rudy; OLSEN, Timothy. 'Managing the Human Cloud', MIT Sloan Management Review, Winter, 2012.

KANTOR, Jodi; STEITFELD, David. "Inside Amazon: Wrestling Big Ideas in aBruising Workplace", The New York Times, 15 August, 2015 
KINNIE, N., HUTCHINSON, S.; PURCELL, J. “Fun and Surveillance”: The Paradox of High Commitment Management in Call Centres', International Journal of Human Resource Management, v. 11, n. 5, 2000, pp. 964-985.

KITTUR, Aniket NICKERSON, Jeffrey V.; BERNSTEIN, Michael S.; GERBER, Elizabeth; SHAW, A., ZIMMERMAN, J., LEASE, M.; HORTON, J.J. 'The Future of Crowd Work' 2013. Disponível em: <http://papers.ssrn.com/sol3/papers.cfm?abstract_ $\mathrm{id}=2190946$. Acesso em: 13 set. 2019.

LEVER-TRACY, Constance. 'Fordism Transformed? Employee Involvement and Workplace Industrial Relations at Ford', Journal of Industrial Relations, v. 32, n. 2, 1990, pp. 179-196.

LEWCHUK, W.; ROBERTSON, David. 'Production Without Empowerment: Work Reorganization from the Perspective of Motor Vehicle Workers', Capital and Class, 63, 1997, pp. 37-65.

LEWCHUK, Wayne; STEWART, Paul; YATES, Charlotte. 'Quality of Working Life in the Automobile Industry: A Canada-UK Comparative Study', New Technology, Work and Employment, v. 16, n. 2, 2001, pp. 72-87.

LICHTENSTEIN, Nelson. Wal-Mart: The Face of Twenty-First Century Capitalism. New York: New Press, 2006.

LINHART, Robert. The Assembly Line. London: John Calder, 1981.

LIPIETZ, Alain. 'Towards Global Fordism?', New Left Review, v. I, n. 132, 1982, pp. 31-47. LIPIETZ, Alain. Mirages and Miracles: Crisis in Global Fordism. London: Verso, 1987.

LIPIETZ, Alain. Towards a New Economic Order: Post-Fordism, Ecology and Democracy. Cambridge: Polity Press, 1992.

LIPIETZ, Alain. "The Post- Fordist World: Labour relations, international hierarchy and global; ecology" Review of International Political Economy, v. 4, n. 1, 1995, pp. 1-41 MANDL, I. New Forms of Employment, Office of the European Union, 2015.

MARANTZ, Andrew. 'My Summer in an Indian Call Centre', Mother Jones, July/ August, 2011.

MARGLIN, S.S; SHOR, J.B. The Global Age of Capitalism: Reinterpreting the Post-war Experience, Oxford: Oxford University Press, 1992.

MARVIT, Moshe Z. 'How Crowdworkers Became the Ghosts in the Digital Machine', The Nation, February 4, 2014.

MASSEY, Doreen; MEGAN, Richard. The Anatomy of Job Loss. London: Methuen, 1982. MCCHESNEY, Robert. Digital Disconnect: How Capitalism is Turning the Internet Against Democracy. New York: The New Press, 2013 (320).

MCCHESNEY, Robert. (2014) 'Interview with Sally Birch "How Can the Internet be De-Monopololised?", 16 April. Available at http://twn.my/title2/resurgence/2014/287-288/covero5.htm (accessed 23 April 2014). 
MCGETTIGAN. The Great University Gamble: Money, Markets and the Future of Higher Education. London, Pluto Press, 2013.

MCKINLAY, Alan; STARKEY, Ken. 'After Henry: Continuity and Change in Ford Motor Company', Business History, v. 36, n. 1, 1994, pp. 184-205.

MERRILL, J. "Forget India...call centres are moving to Bulgaria" The Independent 14 November, 2013. Accessed at http://www. Independent,co.uk/news/world/Europe.

MILKMAN, Ruth. Farewell to the Factory: Auto Workers in the Late Twentieth Century. Berkeley: University of California Press, 1997.

MITCHELL, Tom; SEBASTOPUlO, Demetri. 'China Labour Activism: Crossing the Line', Financial Times, 14 May, 2014.

MONBIOT, George. 'Sick of This Market-Driven World? You Should Be.. The Guardian, 6 August, 2014. Disponível em: <http://www.theguardian.com/commentisfree/2014/aug/05/neoliberalism-mental-health-rich-poverty-economy >. Acesso em: 12 set. 2019.

MUNCK, Ronaldo. Globalisation and Labour: The New Great Transformation. London: Zed Books, 2002.

MURRAY, Robin. 'Life After Henry Ford', Marxism Today. October, 1988, pp. 8-13.

MURRAY, Robin. 'The State After Henry', Marxism Today. May, 1991, pp. 22-27.

NICHOLS, Theo; CAM, Surhan. Labour in a Global World. Basingstoke: Palgrave Macmillan, 2005.

NOLAN, H. (2014a) 'Amazon is a Time Thief, by an Amazon Employee', Gawker, 30 April 2014, Gawker.com/amazon-is-a-time-thief-by-an-Amazon-employee

NOLAN, H. (2014b) 'Inside Amazon's Bizarre Corporate Culture' Gawker, 1 May, 2014, Gawker.com/inside-amazons-bizarre-corporate-culture

NOLAN, H. 'Working at Amazon is "a soul crushing experience”, Gawker, 5 August 2014, Gawker.com/working-at-amazon-is-a-soul-crushing-experienceOffshore Insights (2006) 'Off Shore and Near Shore ITO and BPO Salary Report', Market Report Series, v. 4, n. 4, 2014C, June.

OXFORD ECONOMICS. UK Out-Sourcing Across Public and Private Sectors, Oxford: 2012.

PALM, Goran. The Flight From Work. Cambridge: Cambridge University Press, 1977 (204).

PARKER, George. The Unwinding: The Inner History of the New America. London: Faber and Faber, 2013 (434).

PARKER, M.; SLAUGHTER, J. Management by Stress: The Team Concept in US Auto. Detroit: Labor Notes, 1988.

PARTRIDGE, H. Italy's Fiat in Turin: Labour Struggles and Capital's Response. Doctoral thesis, Durham University, 1986. 
PFEFFER, Richard. Working For Capitalism. New York: Columbia University Press, 1979. PIORE, Michael J.; SABEL, CharlesE. The Second Industrial Divide. New York: Basic Books, 1984.

POLANYI, Karl. The Great Transformation: The Political and Economic Origins of Our Time, Boston. Beacon Press, 1994.

PRESS Trust of India, (2014) “India losing 70\% voice and call centre business to Philippines: report”, 6 April accessed at http//: www.profit,ndtv.com/news/industries/-articleindia-losing-70-voice-and-call-centre-business-to-phillipinesreport-384804

REICH, Robert. The Work of Nations. New York: Vintage Books, 1991.

RINEHART, James; HUXLEY, Christopher; ROBERTS, David. Just Another Car Factory? Lean Production and its Discontents. Ithaca, NY: ILR Press, 1997.

RITZER, George. The McDonaldization of Society. Thousand Oaks, CA: Pine Forge Press, 1993.

ROBERTS, D. 'Services on the Assembly Line: New Technology Brings the Methods of Henry Ford to Offices Around the Globe', Financial Times, 15 April, 2004, p. 11.

ROSS, Joel; IRANI, Lilly; SIX SILBERMAN, M.; ZALDIVAR, Andrew; TOMLISNSON, Bill. 'Who Are the Crowdworkers? Shifting Demographics in Mechanical Turk', in Extended Abstracts of Proceedings of CHI Conference on Human Factors in Computing Systems. New York: ACM, 2010, pp. 2863-2872.

SARKAR, Santanu. 'Murder at Work: Extended Conflict and Aggression in Indian Factories', Work Organisation, Labour and Globalisation, v. 9, n. 1, 2015.

SAYER, Andrew; WALKER, Richard. The New Social Economy. Cambridge, MA: Blackwell, 1992.

SCHOLZ, T. (2015) "Think outside the Boss: Cooperative alternatives to the sharing economy", $8^{\text {th }}$ Annual Eric N. Schocket Memorial Lecture on Class and Culture. $w w w$. publicseminar.org/2015/04/think-outside-the-boss

SEIDLER, Edouard. Let's Call it Fiesta: The Autobiography of Ford's Project Bobcat. London: Patrick Stevens, 1976.

SEWELL, Graham. 'The Discipline of Teams: The Control of Team-based Industrial Work through Electronic and Peer Surveillance', Administrative Science Quarterly, v. 43 , n. 2,1998 , pp. 397-429.

SEWELL, Graham; WILKINSON, Barry. 'Someone to Watch Over Me: Surveillance,

Discipline and the JIT Labour Process', Sociology, v. 26, n. 2, 1992, pp. 271-289.

SPRIGG, Christine Ann; JACKSON, Paul Russel. 'Call Centres as Lean Service

Environments: Job Related Strain and the Mediating Role of Work Design', Journal of Occupational Health Psychology, v. 11, n. 2, 2006, pp. 197-212.

STANDING, Guy. Work after Globalisation: Building Occupational Citizenship, Cheltenham: Edward Elgar, 2009. 
STANDING, Guy. The Precariat: A New Dangerous Class. London: Bloomsbury, 2011.

STARKEY, Ken; MCKINLAY, Alan. 'Managing For Ford', Sociology, v. 28, n. 4, 1994, pp. 957-990.

STEWART, Paul; RICHARDSON, Mike; DANFORD, Andy; MURPHY, Ken; RICHARDSON, Tony; WASS, Vicki. We Sell Our Time No More: Workers' Struggles Against Lean Production in the British Car Industry. London: Pluto Press, 2009.

STRANGE, Susan. Casino Capitalism: Manchester: Manchester University Press, 1986. TAYLOR, Frederick Winslow. The Principles of Scientific Management. Mineola, NY:

Dover, 1998.

TAYLOR, Phil; BAIN, Peter. “An Assembly Line in the Head”: Work and Employee Relations in the Call Centre', Industrial Relations Journal, v. 30, n. 2, 1999, pp. 101-117. TAYLOR, Phil; HYMAN, Jeff; MULVEY, Gareth; BAIN, Peter. 'Work Organization, Control and the Experience of Work in Call Centres', Work, Employment and Society, V. 16, n. 1, 2002, pp. 133-150.

TAYLOR, Steve. 'Emotional Labour and the New Workplace. In: THOMPSON Paul; WARHURST, Chris. (eds.) Workplaces of the Future. Basingstoke: Macmillan, 1998. TRIVEDI, Anita. 'Global Capitalism, Workers' Spaces and Processes of Selective Inclusion/ Exclusion: Findings from a Newly Industrializing Area in India, Occasional Paper n. 80, 2007, De Montfort University.

URRY, John. Offshoring. Cambridge: Polity Press, 2014.

VAIDYANATHAN, Rajini. 'India's Call Centre Growth Stalls', BBC News Mumbai, 27, September, 2011. Disponível em: <http://www.bbc.co.uk/news/magazine-15060641.> Acesso em: 11 set. 2019.

VIDAL, M. 'Manufacturing Empowerment? “Employee Involvement”. In: The Labour Process and Fordism', Socio-Economic Review, 5, 2007, pp. 197-232.

VIDAL, M. (2011) 'Reworking Postfordism - Labour Process Versus Employment Relations', Sociology Compass, 5, 273-286.

VIDAL, M. 'On the Persistence of Labour Market Insecurity and Slow Growth. In: the USA: Reckoning with the Waltonist Growth Regime', New Political Economy, v. 17, n. 5, 2012, pp. 543-564.

VIDAL, M. 'Postfordism as a Dysfunctional Accumulation Regime: A Comparative Analysis of USA, the UK and Germany', Work, Employment and Society, 27, 2013a, pp. 451-471.

VIDAL, M. 'Low-Autonomy Work and Bad Jobs in Post-Fordist Capitalism', Human Relations, 66, 2013b, pp. 587-616.

WALKER, Chris; HATLEY, Morgan. 'The Cultured Shock of India's Call Centers'. 2012. Disponível em: <http://www.forbes.com/sites/morganhartley/2012/12/16/the-culture-shock-of-indias-call-centers/>. Acesso em: 11 set. 2019. 
WALLRAFF, Gunter. The Undesirable Journalist. London: Pluto Press, 1977.

WILLIAMS, K. HASLAM, H; WILLIAMS, J. 'Ford versus "Fordism": The Beginning of Mass Production?, Work Employment and Society, v. 6, n. 4, 1992, pp. 517-515.

WILSON, Tom. 'The Proletarianisation of Academic Labour', Industrial Relations Journal, v. 22, n. 4, 1991, pp. 250-262.

WOMACK, James P.; JONES, Daniel T.; ROOS, Daniel. (1990) The Machine that Changed the World. New York: Macmillan.

WOOD, S. 'On the Line', Car, July, 1987, pp. 140-147.

WRIGHT, Erik Olin. Envisaging Real Utopias, London: Verso, 2010.

ZHANG, Lu. Inside China's Automobile Factories: The Politics of Labor and Worker Resistance, Cambridge: Cambridge University Press, 2014.

Recebido em: 16/07/2019

Aprovado em: 25/11/2019

\section{Como citar este artigo:}

BEYNON, Huw. As novas realidades do trabalho. Contemporânea - Revista de Sociologia da UFSCar, v. 9, n. 2, maio - agosto. 2019, pp. 613-651. 